\title{
Jominy End Quench Test of Martensitic Stainless Steel X30Cr13
}

\author{
Pierre Landgraf ${ }^{1, *} \mathbb{C}^{\circ}$, Peter Birnbaum ${ }^{2}{ }^{\oplus}$, Enrique Meza-García ${ }^{2}{ }^{-}$, Thomas Grund ${ }^{1}$, Verena Kräusel ${ }^{2}$ \\ and Thomas Lampke 1 (1)
}

1 Materials and Surface Engineering Group, Institute of Materials Science and Engineering, Chemnitz University of Technology, D-09107 Chemnitz, Germany; thomas.grund@mb.tu-chemnitz.de (T.G.); thomas.lampke@mb.tu-chemnitz.de (T.L.)

2 Professorship for Forming and Joining, Institute for Machine Tools and Production Processes, Chemnitz University of Technology, D-09107 Chemnitz, Germany; peter.birnbaum@mb.tu-chemnitz.de (P.B.); enriquemeza@daad-alumni.de (E.M.-G.); verena.kraeusel@mb.tu-chemnitz.de (V.K.)

* Correspondence: pierre.landgraf@mb.tu-chemnitz.de

Citation: Landgraf, P.; Birnbaum, P.; Meza-García, E.; Grund, T.; Kräusel, V.; Lampke, T. Jominy End Quench Test of Martensitic Stainless Steel X30Cr13. Metals 2021, 11, 1071. https://doi.org/10.3390/ met11071071

Academic Editors: C. Issac Garcia and João Pedro Oliveira

Received: 19 March 2021

Accepted: 18 June 2021

Published: 3 July 2021

Publisher's Note: MDPI stays neutral with regard to jurisdictional claims in published maps and institutional affiliations.

Copyright: (c) 2021 by the authors. Licensee MDPI, Basel, Switzerland. This article is an open access article distributed under the terms and conditions of the Creative Commons Attribution (CC BY) license (https:// creativecommons.org/licenses/by/ $4.0 /)$.

\begin{abstract}
In this study, the influence of thermal treatments on the properties of the martensitic stainless steel X30Cr13 (EN 10088-3: 1.4028) were investigated. These steels are characterized by a high hardness as well as corrosion resistance and can be specifically adjusted by heat treatment. In particular, the austenitizing temperature $\vartheta_{A}$ and cooling rate $\dot{T}$ affect the hardness and corrosion properties of martensitic stainless steels. In order to investigate these influences, the Jominy end quench tests were performed at varying austenitizing temperatures. The aim is to determine the hardness and corrosion properties as a function of the austenitizing temperature and the cooling rate. The austenitizing temperature strongly influences the solubility of alloying elements within the austenitic lattice as well as the grain size, and thus affects both precipitation and phase transformation kinetics. In consequence, different austenitizing temperatures lead to different macroscopic material properties, like hardness and pitting corrosion potential. The heat treatment was simulated using finite element (FE) method and compared with time-temperature sequences measured at different locations of the Jominy end quench sample using thermocouples. That allows determining the cooling rate $\dot{T}$ between $800^{\circ} \mathrm{C}$ and $500^{\circ} \mathrm{C}$ and to assign it to each location of the Jominy end quench sample. The numerical estimations were in close conformity with the experimental values. By assigning the hardness and pitting corrosion potentials to the respective cooling rates as a function of the austenitizing temperature, it is possible to determine optimum process windows for the required properties.
\end{abstract}

Keywords: heat treatment; martensitic stainless steel; jominy end quench test; austenitizing temperature; cooling rate; pitting corrosion potential; hardness; FEM

\section{Introduction}

Martensitic stainless steels are commonly used for the manufacture of components with high mechanical strength and moderate corrosion resistance, operating at either high or low temperatures. The service properties of martensitic stainless steels depend to a large extent on the microstructure resulting from the heat treatment and can therefore be adjusted in a tailored manner. The production of sheet metal and tubular components from martensitic stainless steels is mainly carried out by cold forming. The steels are in the solution-annealed or soft-annealed condition. The desired mechanical properties are achieved by heat treatment, hardening and tempering, which takes place after forming process. Despite their "soft" delivery condition, martensitic stainless steels reach the limits of their formability during cold forming. This limited formability can be overcome by increasing the forming temperature above the recrystallization temperature (hot stamping or press hardening). By selectively combining forming and heat treatment in a single process step, i.e., thermomechanical treatment (TMB), there is great potential for using martensitic 
stainless steels in the manufacture of complex component structures and thus opening up new fields of application, especially with regard to their high lightweight potential.

The main objective of the research project is determining the influence of the process parameters, i.e., austenitizing temperature, cooling rate, strain, and strain rate, on the resulting mechanical properties and corrosion resistance of hot deep drawn sheet parts [1]. However, due to the wide range of variables and their complex iteration among them, this work focused first on the experimental determination of the effect of heat treatment on the mechanical and corrosion resistance properties by intentionally excluding the effect of strain and strain rate. This is important because later, with the help of these results, the effect of the strain and strain rate in hot deep drawing sheet metal forming trials can be clearly seen. Therefore, in this initial research, the effect of the heat treatment parameters on the phase transformations in relation to the dissolution and precipitation of precipitates, as well as on the corrosion resistance of the martensitic stainless steel was determined. For this purpose, the most suitable alternative for this analysis was characterizing the $\mathrm{X} 30 \mathrm{Cr} 13$ alloy by the Jominy end quench test.

The Jominy end quench test of martensitic stainless steel makes it possible to investigate different cooling rates as a function of different austenitizing temperatures [2]. Depending on the austenitizing temperature, different contents of alloying elements are present in solid solution in the austenitic lattice [3,4]. This influences the precipitation and transformation kinetics during cooling as well as the resulting properties of the heat treated material, such as hardness and corrosion behavior [3,4]. Furthermore, the grain size is influenced by the austenitizing temperature. In particular, strong grain growth takes place at austenitizing temperatures in which the carbides are dissolved [5]. It is common state of knowledge, that in martensitic transformation of steels, the resulting maximum hardness depends on the present carbon content (see, e.g., in [6]). With increasing carbon content the tetragonality (c/a ratio) of the martensitic lattice increases, and thus the hardness level rises.

The austenite stabilizer carbon simultaneously leads to a decrease in the martensite start $\mathrm{M}_{\mathrm{S}}$ and finish $\mathrm{M}_{\mathrm{F}}$ temperature with increasing content. If the martensite finish temperature is below room temperature, retained austenite remains if no further cooling is actively forced. According to the mixing rule, the total hardness results from the volume fractions of the respective structural constituents multiplied by the respective hardness of the structural constituents. Due to this rule, despite a higher carbon content, the integrated total hardness may actually decrease, e.g., due to the content of retained austenite.

The corrosion behavior is largely dependent on the chromium content $[3,4,7]$. Starting from a chromium mass content of approximately $10-12 \%$, stainless steels form a chromium oxide layer (passive layer), which—after its initial formation-acts as oxygen barrier and prevents deeper volumes of the steel from further oxidation. To provide this property, the chromium atoms must be homogeneously dissolved within the austenitic lattice and, after cooling, in the martensitic lattice. In high-alloy martensitic stainless steels, this dissolved chromium content depends on the austenitizing temperature $[2,4,7]$ because it affects the solubility and distribution of chromium carbides in that state. The corrosion resistance is also influenced by the cooling rate during martensitic transformation hardening. Depending on the cooling rate, diffusion may lead to formation and precipitation of chromium carbides, decreasing both the homogeneous distribution of chromium and carbon within the aimed martensitic phase. This leads to local chromium depletion and thus deteriorating its resistance to corrosion. These chromium carbides occur in the grain interior and at grain boundaries [2,4].

In further research, the influence of austenitizing on the microstructure, in particular the carbide volume fraction and distribution, and the properties after heat treatment were investigated [8-12]. In [8], it is concluded that the amount of $\mathrm{M}_{23} \mathrm{C}_{6}$ carbides of a 0.45C$13 \mathrm{Cr}$ martensitic stainless steel can be varied by controlling the thermal parameters. This is attributed to carbide dissolution and precipitation processes that occur during heating and cooling. Rosemann et al. [9] point out that due to the different diffusion rates of carbon and chromium, the corrosion resistance must not always correlate with the hardness of 
martensitic stainless steels. Therefore, it is useful to investigate both properties as a function of the heat treatment parameters. Further studies on the influence of heat treatment of martensitic stainless steels on properties such as deep drawability, hot sheet formability, notched bar impact energy or tool wear can be found in [13-15].

In order to undertake a comprehensive analysis, this work has been divided into three sections: The first deals with the experimental determination of the effect of austenitizing temperature and quenching rate on the hardness and corrosion resistance of the martensitic stainless steel X30Cr13 steel by the Jominy end quench test. In the second section, the Jominy end quench test has been simulated numerically by means of DEFORM ${ }^{\mathrm{TM}}-\mathrm{HT}$ software in order to analyze in detail the temperature changes and simultaneously the microstructural changes developed by the alloy. A metallurgical analysis of the X30Cr13 alloy based on thermodynamic calculations obtained with JMatPro ${ }^{\circledR}$ software was previously performed to determine the material properties of the alloy required as input data for the simulation. Based on the results of the simulation and the experimental temperature measurement during the Jominy end quench test, it was possible to reliably analyze and to determine the cooling rate at each location of the Jominy end quench test sample. As a summary in the third section, application-optimized process windows could be established by combining the resulting hardness and corrosion properties as a function of the austenitizing temperature and cooling rate.

Based on the complex metallurgical processes that occur in martensitic stainless steels due to the high content of allyoing elements, especially chromium, the following research questions arise. The answers to these questions will allow both an application-related and a processing-related optimization of their heat treatment or combined thermomechanical treatment:

1. How do austenitizing temperature and quenching rate influence the phases and phase fractions in the resulting microstructures of the differently treated steel?

2. How do the phase fractions of martensite, retained austenite, and chromium carbide, which depend on the heat treatment and the (local) carbon content, influence resulting integral mechanical properties (e.g., hardness)?

3. What corrosion properties show the different microstructures with different phases or phase fractions/proportions and locally different chemical composition?

The investigations described in the following are geared towards answering these questions and enable a result-oriented discussion of the obtained results. The applied methods include experimental investigations, thermodynamic calculations, and numerical simulations.

\section{Experimental Setups and Approach on Simulation}

The chemical composition of the X30Cr13 material used in this work is listed in Table 1. The initial state of the steel is hot rolled and annealed, see Figure 1. The hardness is $\sim 202 \pm 5$ HV10.

Table 1. Chemical composition of the investigated steel $\mathrm{X} 30 \mathrm{Cr} 13$ by spectrometric analysis (balance $\mathrm{Fe}$ ).

\begin{tabular}{lrrrrrrrrrr}
\hline Elements & $\mathbf{C}$ & $\mathbf{C r}$ & $\mathbf{S i}$ & $\mathbf{M o}$ & $\mathbf{M n}$ & $\mathbf{P}$ & $\mathbf{S}$ & $\mathbf{N i}$ & $\mathbf{V}$ & $\mathbf{C u}$ \\
\hline $\begin{array}{l}\text { Mass } \\
\text { fractions } / \%\end{array}$ & 0.37 & 13.76 & 0.36 & 0.06 & 0.38 & 0.032 & 0.001 & 0.15 & 0.045 & 0.22 \\
\hline
\end{tabular}




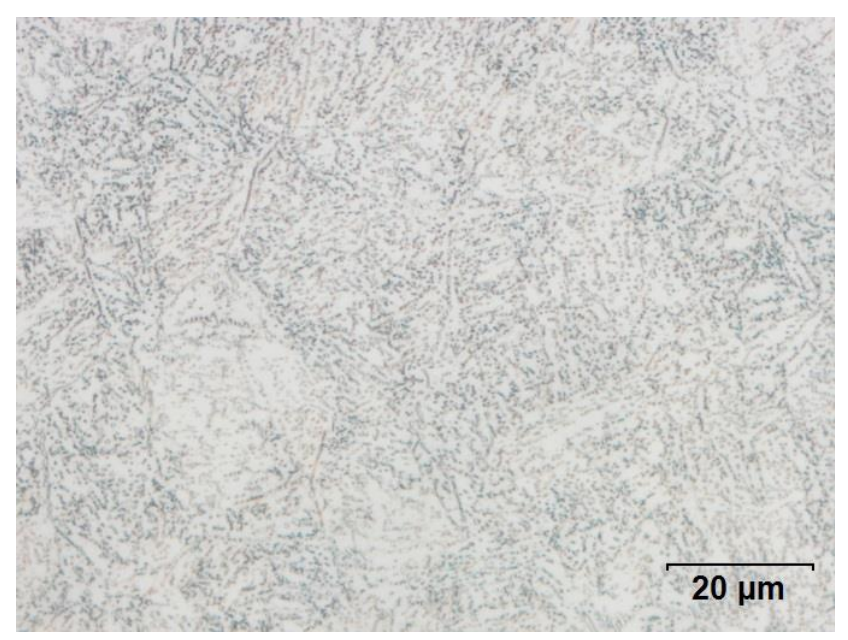

Figure 1. Homogeneous initial microstructure of $\mathrm{X} 30 \mathrm{Cr} 13$ (V2A etchant). A ferritic matrix with chromium carbides is visible.

The Jominy end quench test was performed according to EN ISO 642 [16]. The Jominy end quench test was carried out for three different austenitizing temperatures, see Table 2.

Table 2. Austenitizing temperatures in ${ }^{\circ} \mathrm{C}$. The holding time including heating was $50 \mathrm{~min}$.

\begin{tabular}{llll}
\hline Austenitizing Temperature $/{ }^{\circ} \mathrm{C}$ & 1000 & 1050 & 1100 \\
\hline
\end{tabular}

The heating and holding times for each test were approximately $50 \mathrm{~min}$. After heating in the furnace Nabertherm $\mathrm{N} 11 / \mathrm{H}$, the specimens were placed in a Jominy end quench device, schematically shown in Figure 2, and quenched from the end face with water. Figure 3 shows the chronological sequence of the Jominy end quench test on the basis of the temperature development (recognizable by the red-hot steel) at different times. With increasing distance from the quenched end face, the local cooling rate decreases. According to the work in [16], the Jominy end quench test generally lasts approximately $10 \mathrm{~min}$. After this time, the samples were completely quenched in water.

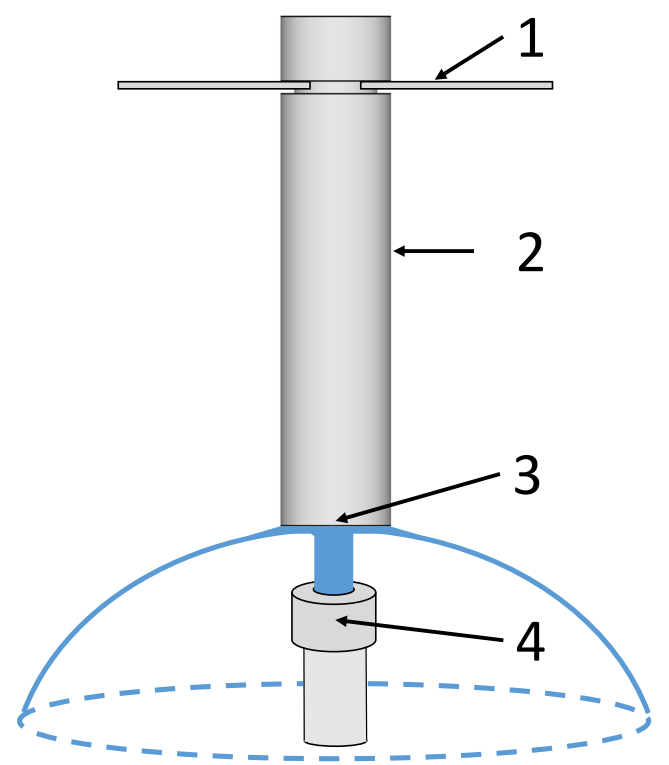

Figure 2. Schematic illustration of the Jominy end quench device based on [16]. (1) Mounting fixture, (2) Jominy test specimen, (3) end face of the test specimen quenched with water, and (4) water spray pipe. 


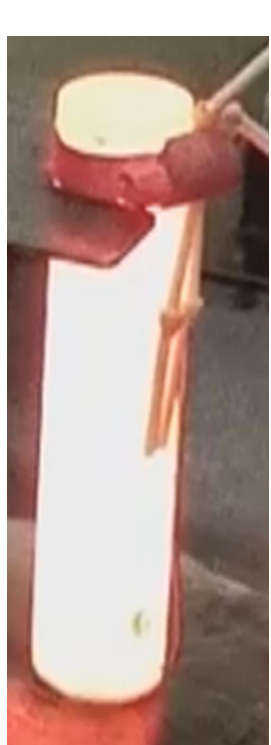

a)

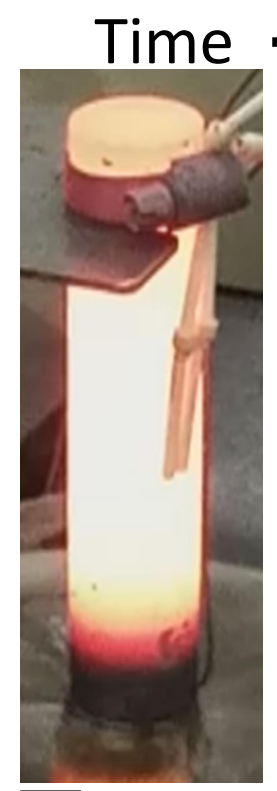

b)

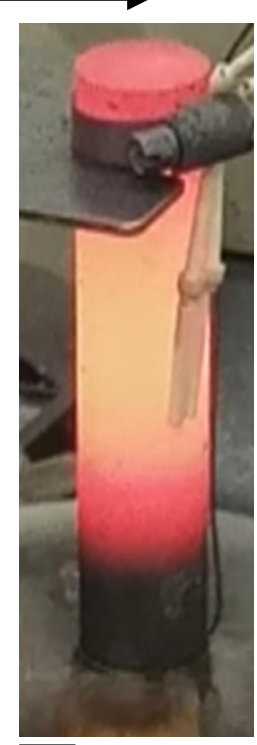

c)

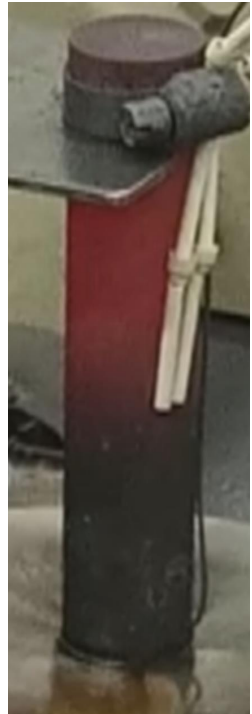

d)

Figure 3. Visible cooling during Jominy end quench test. Thermocouples are applied at the sample. The sample (a) directly after water contact $(\approx 0 \mathrm{~s}),(\mathbf{b})$ after $\approx 15 \mathrm{~s},(\mathbf{c})$ after $\approx 40 \mathrm{~s}$, and (d) after $\approx 120 \mathrm{~s}$.

The geometry of the Jominy end quench test samples is shown in Figure 4. During the experiments, the time-temperature sequences within the samples were measured by use of two type $\mathrm{K}$ thermocouples. One thermocouple $T 1$ was placed at a distance of $5 \mathrm{~mm}$ from the quenched end face in a blind hole of approximately $5 \mathrm{~mm}$ depth, see Figure 4 . The second thermocouple $T 2$ was spot-welded on the lateral surface of the cylindrical specimen at a distance of $50 \mathrm{~mm}$ from the quenched end face, see Figure 4.

After the Jominy end quench test, two test surfaces with a depth of approximately $0.4 \mathrm{~mm}$ to $0.5 \mathrm{~mm}$ each were produced by grinding and polishing. Therefore, the cooling rate at $\mathrm{X}=12 \mathrm{~mm}$ was determined in the FE simulation, compare Figure 14. These were used to measure the local pitting corrosion potential and hardness. The pitting corrosion potential was determined using the micro-corrosion cell with Jaissle potentiostat IMP83 PCT-BC, Keithley-Multimeter 2000, and Burster voltage source Digistant 4462. The microcorrosion cell allows local electrochemical corrosion investigations to be carried out using current density potential curves. The capillary used had a diameter of $800 \mu \mathrm{m}$ and a $0.1 \mathrm{~mol}$ $\mathrm{NaCl}$ solution served as electrolyte. The current density potential curves were recorded at a feed rate of $1 \mathrm{mV} \mathrm{s}^{-1}$ starting from the rest potential up to max. $2000 \mathrm{mV}$. The rest potential varied from $10 \mathrm{mV}$ to $155 \mathrm{mV}$. The reference electrode used was $\mathrm{Ag} / \mathrm{AgCl}(3 \mathrm{~mol} \mathrm{KCl})$ in a classical three-electrode arrangement with platinum counterelectrode. The corrosion behavior was measured starting from the quenched end face at different distances at $1 \mathrm{~mm}$, $2.5 \mathrm{~mm}, 5 \mathrm{~mm}, 10 \mathrm{~mm}, 20 \mathrm{~mm}, 50 \mathrm{~mm}$, and $80 \mathrm{~mm}$.

The Vickers hardness (HV10) was measured from $1 \mathrm{~mm}$ to $100 \mathrm{~mm}$ with a distance of $1 \mathrm{~mm}$. The testing load was $10 \mathrm{kp}(\approx 98.07 \mathrm{~N})$. The hardness measurements were carried out with the automatic hardness tester KB Prüftechnik KB 250 BVRZ.

To make the microstructure visible, $\mathrm{V} 2 \mathrm{~A}$ reagent was used to etch the samples. The chemical composition of the used etching reagent V2A is $100 \mathrm{~mL}$ distilled water, $100 \mathrm{~mL}$ $37 \% \mathrm{HCl}, 10 \mathrm{~mL} 65 \% \mathrm{HNO}_{3}$, and $0.3 \mathrm{~mL}$ Vogel's special reagent. Additionally another etchant according to the authors of [17] consisting of $925 \mathrm{~mL}$ ethanol, $25 \mathrm{~g}$ picric acid, and $50 \mathrm{~mL}$ hydrochloric acid was used to make retained austenite more visible.

Optical microscopy images were taken using Olympus GX51. The grain sizes were determined by comparing the optical microscopy images with the reference series from the standard according to the authors of [18]. Furthermore, microstructure images were obtained by Scanning Electron Microscopy (SEM) and the local chemical composition, 
especially the chromium content, was determined by an Energy-Dispersive X-ray detector (EDX). These investigations were performed on the Zeiss LEO VP 1455 SEM with an X-Flash $3001 \mathrm{EDX}$ detector. An accelerating voltage of $20 \mathrm{kV}$ and a working distance (WD) between $6.2 \mathrm{~mm}$ to $7.5 \mathrm{~mm}$ were used. The detector used is the High-Definition Backscattered Electron Detector (HDBSD). The microstructure investigations were carried out on embedded and prepared (separated, ground, and polished) samples.

The qualification and quantification of the phase fractions were performed by X-ray diffraction (XRD) using a diffractometer D8 Discover (Bruker AXS) with Co-K $\alpha$ radiation. A Co anode X-ray tube as radiation source with an accelerating voltage of $40 \mathrm{kV}$ and a cathode current of $40 \mathrm{~mA}$ was applied to set up the primary beam path. A collimator with a diameter of $0.5 \mathrm{~mm}$ was inserted to perform a locally resolved analysis by XRD depending on the distance of the quenched end face. The detector used for the measurements is a LYNXEYE XE-T. The quantification of the phases was performed by the Rietveld method. The PDF-2 2014 served as the phase database. The lattice parameters (c and a) of the martensite were also determined by XRD.

The simulation of the Jominy end quench test was carried out using DEFORM ${ }^{\mathrm{TM}}-\mathrm{HT}$. JMatPro $^{\circledR}$ V7.0 was used to calculate the thermodynamically based material data using the chemical composition of the alloy summarized in Table 1. JMatPro ${ }^{\circledR}$ enables the calculation and optimization of temperature-dependent material properties for a variety of technical alloys. This includes the calculation of phase equilibria and transformations (thermodynamic calculations/CalPhaD), isothermal and continuous transformation and precipitation diagrams as well as physical and mechanical properties. Further information can be found in [19]. The required material data were implemented in the FE software. NewtonRaphson was used as iteration method and the used mesh parameters and boundary conditions are summarized in Table 3, Figures 4 and 5. The simulation model describes the temperature and microstructural development during cooling starting from the different austenitizing temperatures.
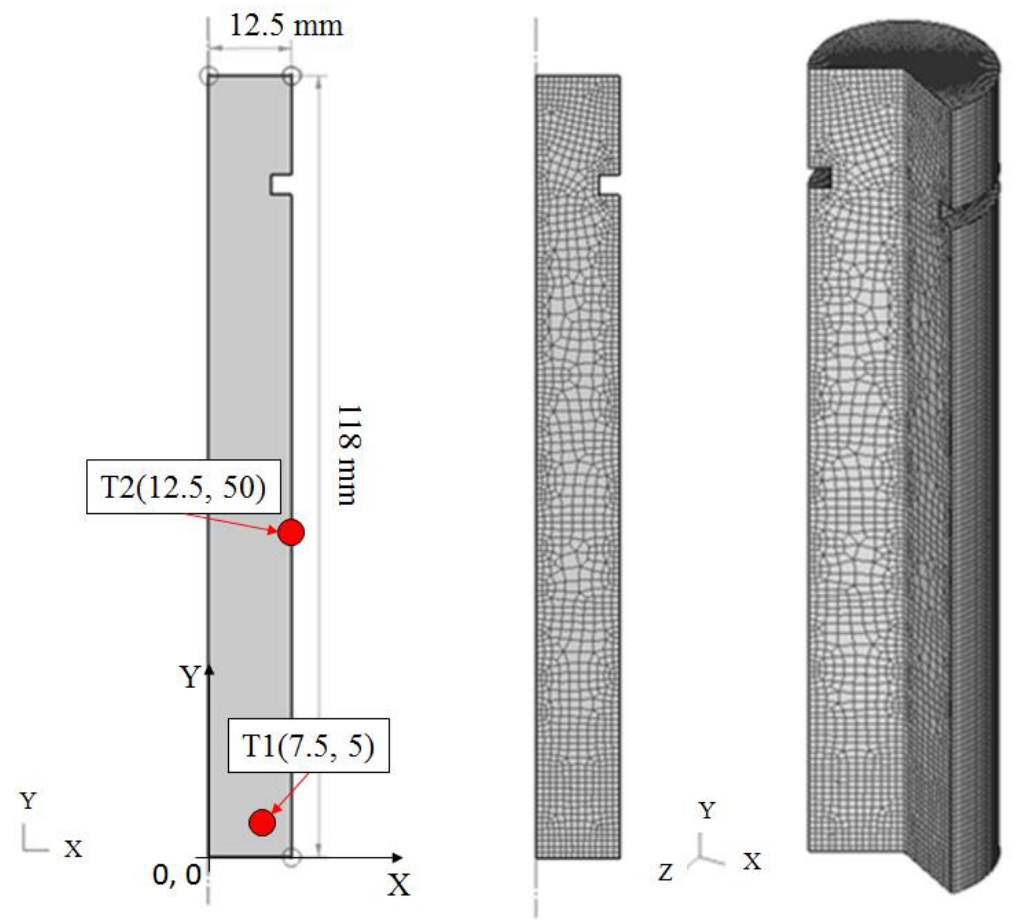

Figure 4. Geometry of Jominy end quench test sample and transfer to FEM (2D and 3D View). 


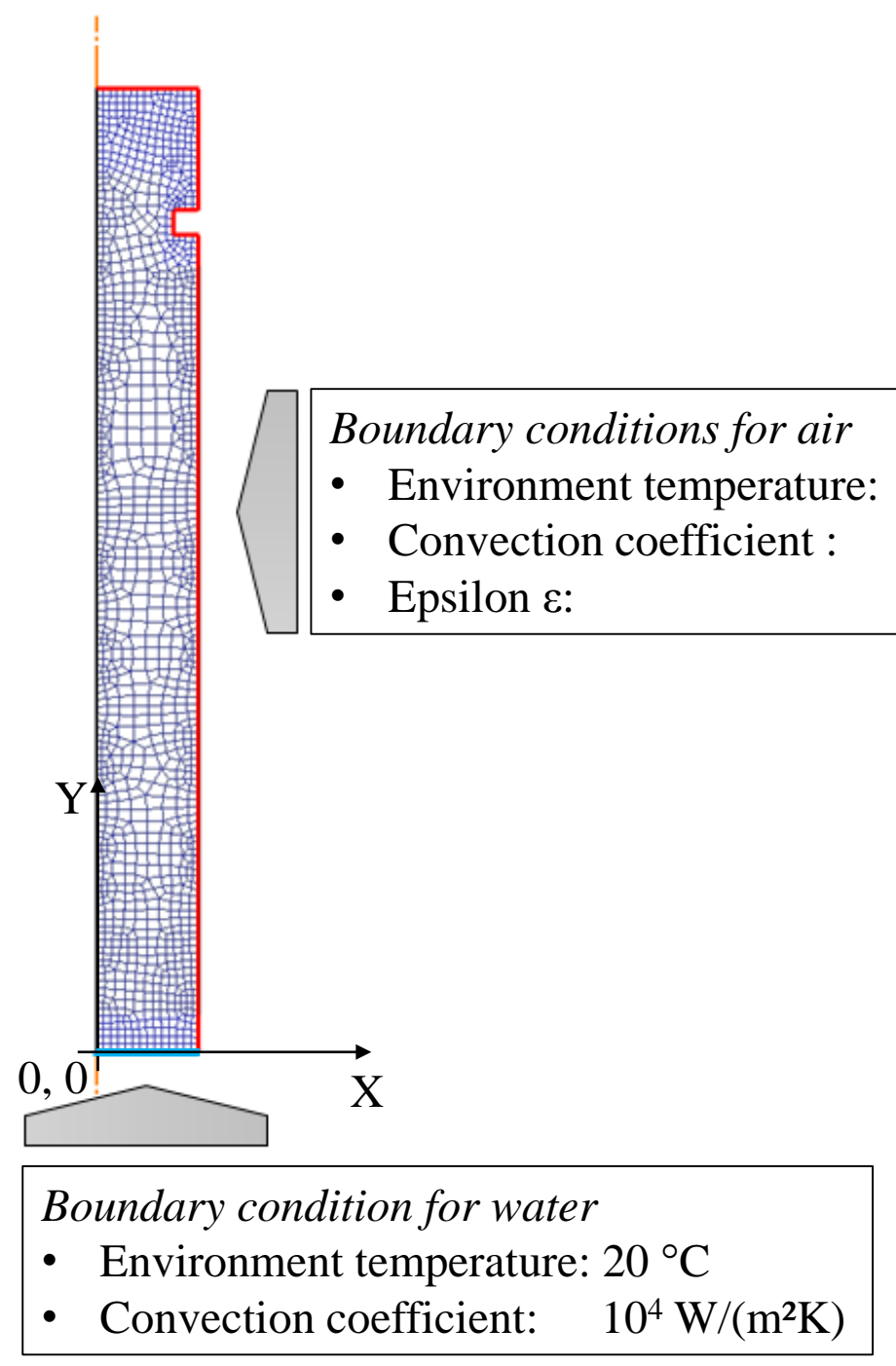

Figure 5. Boundary conditions.

Table 3. 2D Mesh parameters used in DEFORM ${ }^{\mathrm{TM}}-\mathrm{HT}$.

\begin{tabular}{cccc}
\hline Number of Elements & Number of Nodes & Size Ratio & Shape of the Elements \\
\hline 1308 & 1467 & 4 & Square \\
\hline
\end{tabular}

\section{Results and Discussion}

\subsection{Thermodynamic Calculations of X30Cr13 Using JMatPro ${ }^{\circledR}$}

Figure 6 a shows the phase diagram calculated by JMatPro ${ }^{\circledR}$. It can be seen that from approx. $800^{\circ} \mathrm{C}$ with increasing temperature the austenite content increases and the carbide content $\left(\mathrm{M}_{23} \mathrm{C}_{6}\right.$, i.e., $\left.\mathrm{Cr}_{23} \mathrm{C}_{6}\right)$ decreases. This affects the local chemical composition in the austenite, see Figure $6 \mathrm{~b}$. At approximately $1070^{\circ} \mathrm{C}$ maximum solubility is reached, as indicated in Figure 6 and Table 4. 

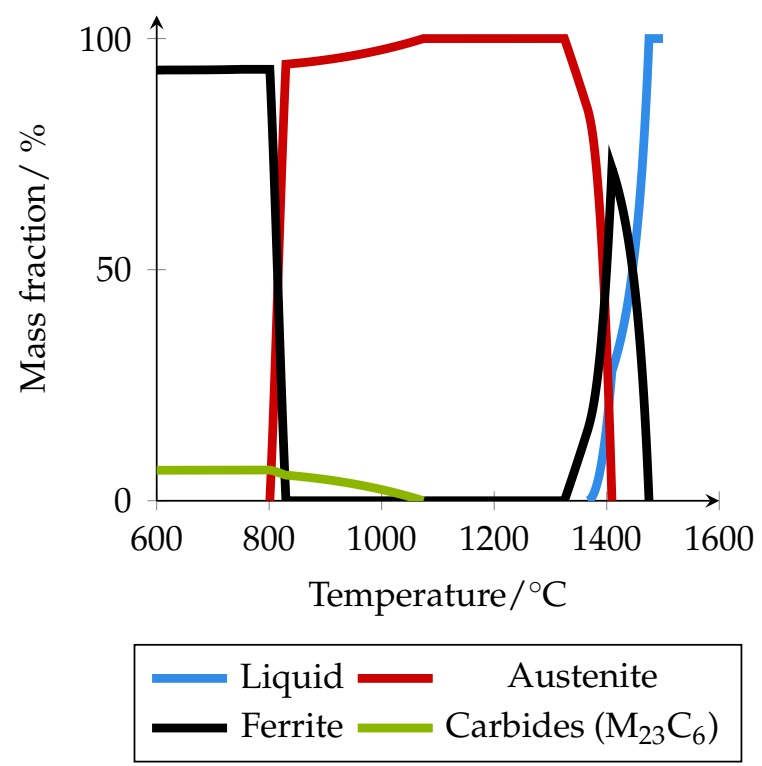

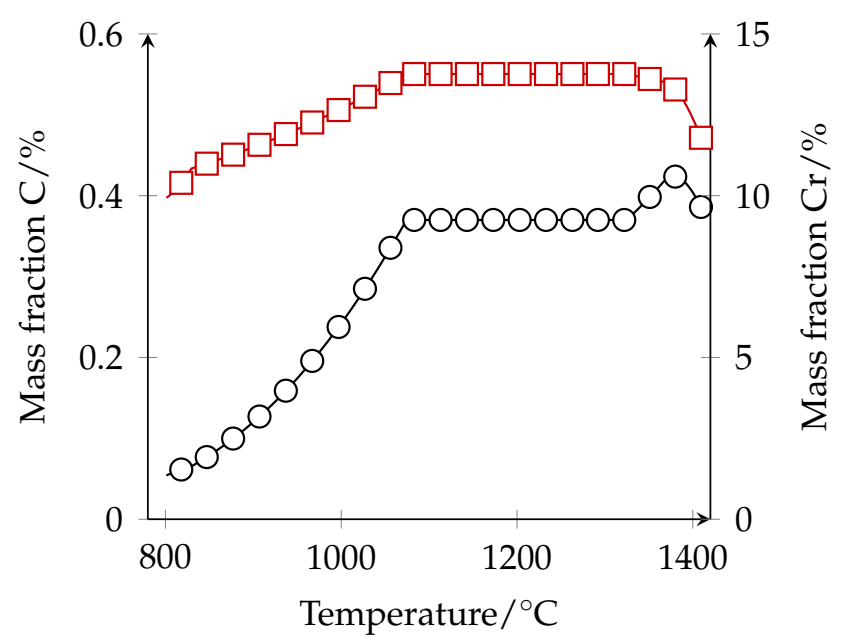

$-\mathrm{C}-\square-\mathrm{Cr}$

(a)

(b)

Figure 6. Thermodynamically calculated phase composition (a) and local chemical composition of austenite (b) in equilibrium for X30Cr13.

Table 4. Calculated composition of X30Cr13 at different temperatures using JMatPro ${ }^{\circledR}$.

\begin{tabular}{cccc}
\hline Temperature $/{ }^{\circ} \mathrm{C}$ & $\mathbf{1 0 0 0}$ & $\mathbf{1 0 5 0}$ & $\mathbf{1 1 0 0}$ \\
\hline Mass fraction of & & & \\
elements in $\gamma / \%$ & & & 0.37 \\
$\mathrm{C}$ in $\gamma$ & 0.24 & 0.32 & 13.76 \\
$\mathrm{Cr}$ in $\gamma$ & 12.69 & 13.39 & \\
\hline Mass fraction & & & 100 \\
phases $/ \%$ & 97.58 & 99.13 & 0 \\
Austenite & 2.42 & 0.87 & \\
$\mathrm{M}_{23} \mathrm{C}_{6}$ & & & \\
\hline
\end{tabular}

This proves that heat treatment at different austenitizing temperatures has a strong effect on the contents of the alloying elements dissolved in the austenite, such as the carbon and chromium content. Furthermore, it has an effect on the microstructural development during cooling as well as on the resulting mechanical and corrosion properties. For example, with increasing carbon content, the martensite start $\mathrm{M}_{\mathrm{S}}$ temperature decreases, as shown in Table 5. The thermal properties required for the simulation (e.g., thermal conductivity or volumetric heat capacity) were calculated by JMatPro ${ }^{\circledR}$ and are shown in Figures 7 and 8.

Table 5. Martensite transformation temperatures as a function of the heat treatment temperatures calculated by JMatPro ${ }^{\circledR}$. $\mathrm{M}_{\mathrm{S}}$ is the temperature at which the transformation of martensite started, and $\mathrm{M}_{50 \%}$ is the temperature at which $50 \%$ of martensite has transformed.

\begin{tabular}{|c|c|c|c|}
\hline Temperature $/{ }^{\circ} \mathrm{C}$ & 1000 & 1050 & 1100 \\
\hline $\mathrm{M}_{\mathrm{S}} /{ }^{\circ} \mathrm{C}$ & 269 & 242 & 228 \\
\hline $\mathrm{M}_{50 \%} /{ }^{\circ} \mathrm{C}$ & 232 & 204 & 189 \\
\hline
\end{tabular}




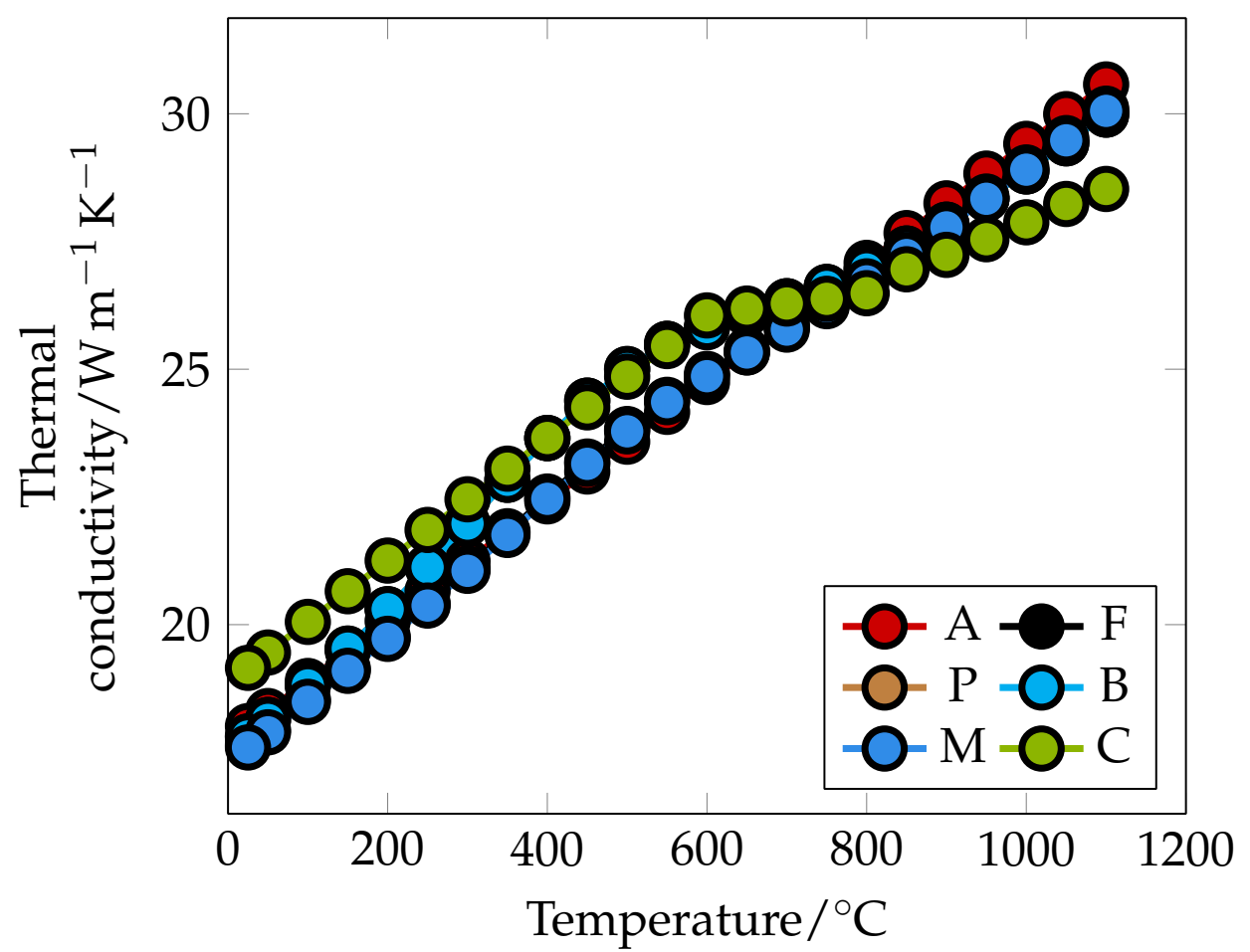

Figure 7. Thermal conductivity of different phases of $\mathrm{X} 30 \mathrm{Cr} 13$ calculated by JMatPro ${ }^{\circledR}$. The abbreviations in the legend mean the following: A: austenite, F: ferrite, P: pearlite, B: bainite, M: martensite and $\mathrm{C}$ : Carbides $\left(\mathrm{M}_{23} \mathrm{C}_{6}\right)$.

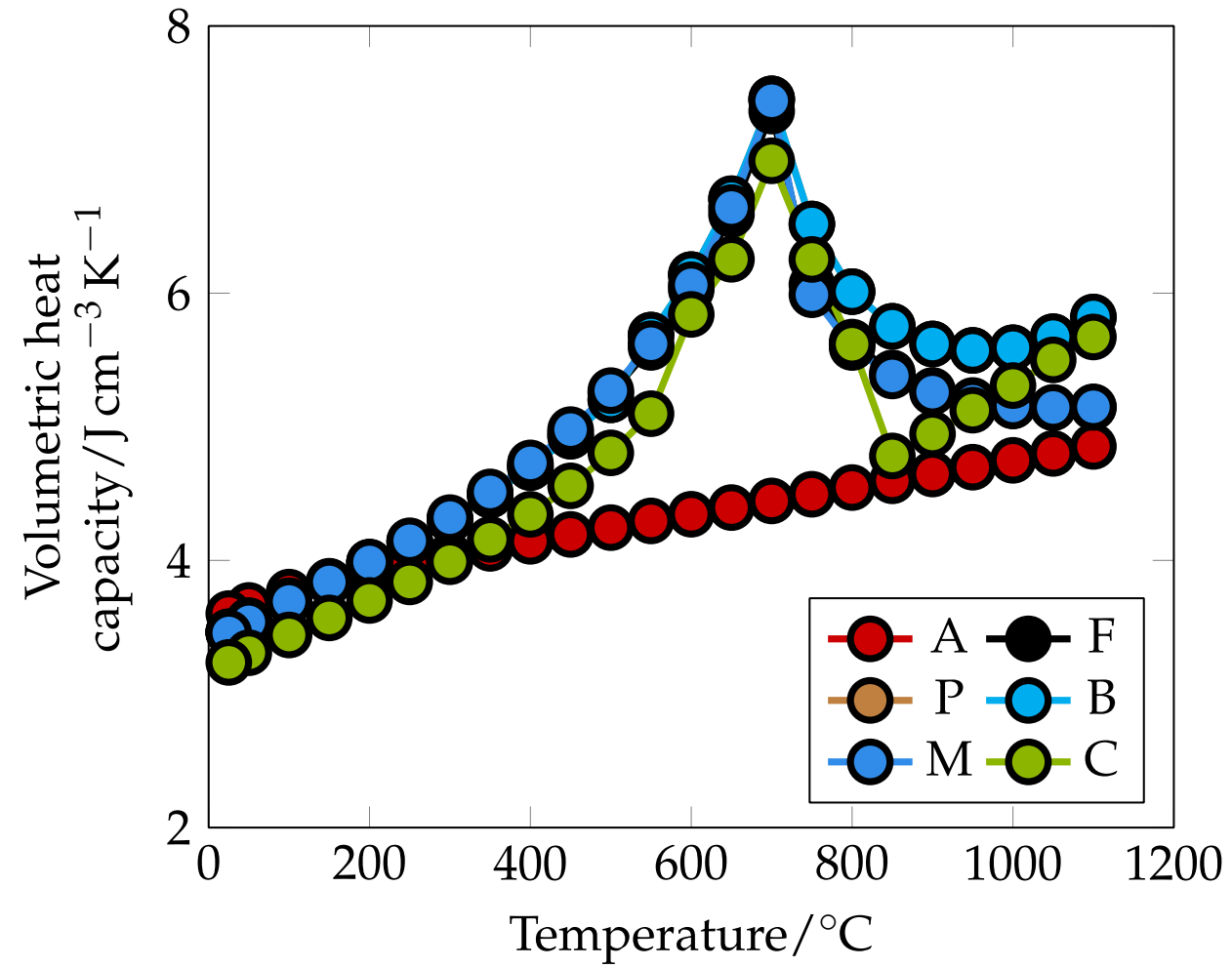

Figure 8. Volumetric heat capacity of different phases of $\mathrm{X} 30 \mathrm{Cr} 13$ calculated by JMatPro ${ }^{\circledR}$. The abbreviations in the legend mean the following: A: austenite, F: ferrite, P: pearlite, B: bainite, M: martensite and $\mathrm{C}$ : Carbides $\left(\mathrm{M}_{23} \mathrm{C}_{6}\right)$. 
Depending on the austenitizing temperature, the respective Time Temperature Transformation (TTT) diagrams were implemented in the FE simulation to take into account the transformation behavior during cooling, see Figures 9 and 10. It can be seen that the microstructure transformation depends on the respective heat treatment temperature and grain size. The diffusion-controlled microstructural transformations (ferrite, pearlite, and bainite) occur after very long periods of time. This is due to the high content of the different alloying elements of this steel (see Table 1 for comparison). In particular, alloying elements such as $\mathrm{Mn}, \mathrm{Cr}$, and Mo slow down the transformation in steel. The alloying elements are redistributed during the transformation into pearlite and bainite, but diffuse much more slowly than carbon [20]. The consideration of the martensite transformation in the FE simulation is realized by specifying $\mathrm{M}_{\mathrm{S}}$ and $\mathrm{M}_{50 \%}$, see Table 5 . These material data were implemented in DEFORM ${ }^{\mathrm{TM}}$-HT.
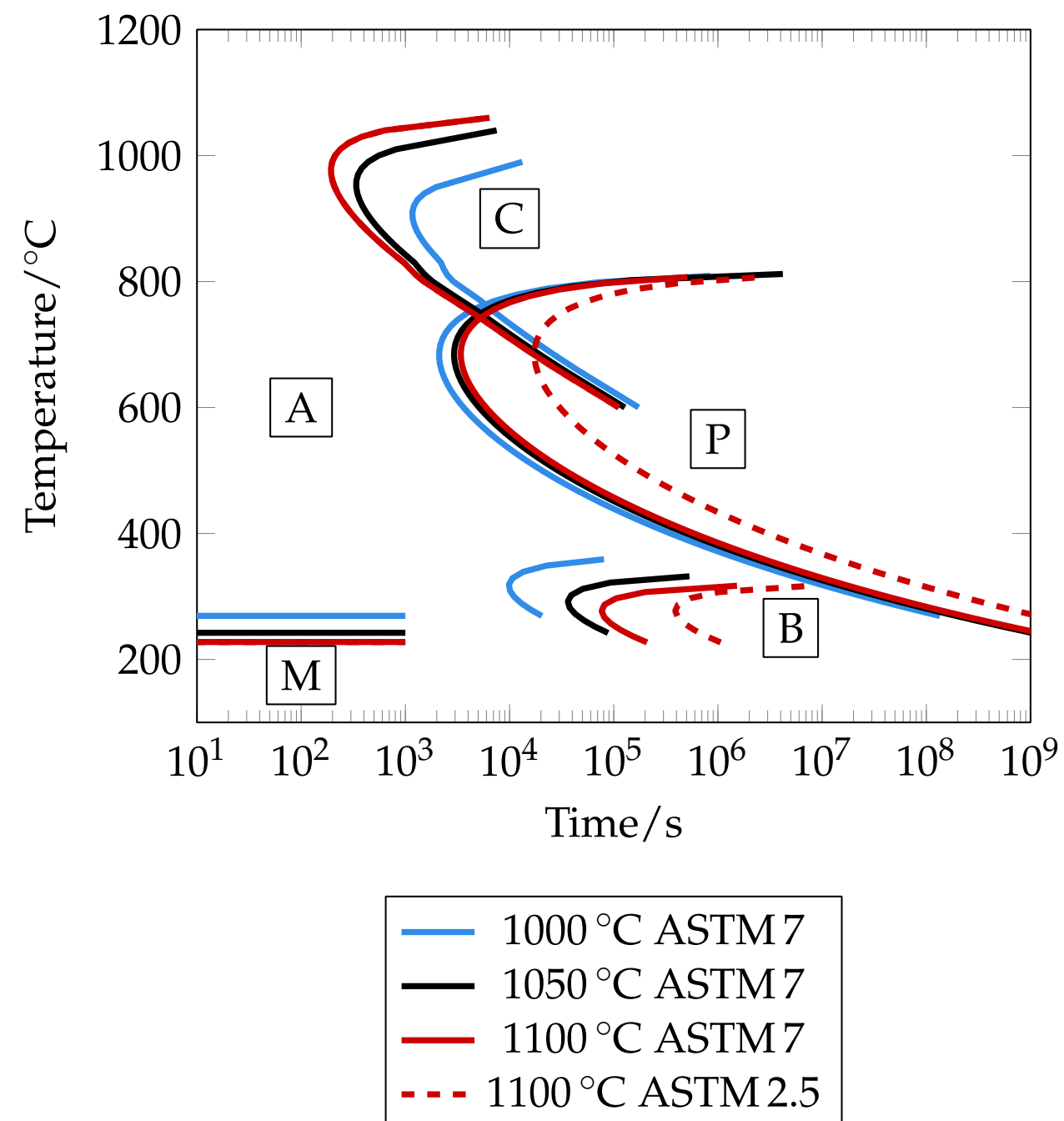

Figure 9. TTT $1 \%$ amount transformed (general steel and stainless steel mode for carbides) ASTM 7 calculated by JMatPro ${ }^{\circledR}$ used for FEM. The abbreviations in the graph mean the following: A: austenite, C: carbides, P: pearlite, B: bainite, M: martensite. In order to show the influence of the grain size, the TTT curve for $1100^{\circ} \mathrm{C}$ and a grain size of ASTM 2.5 were added. 


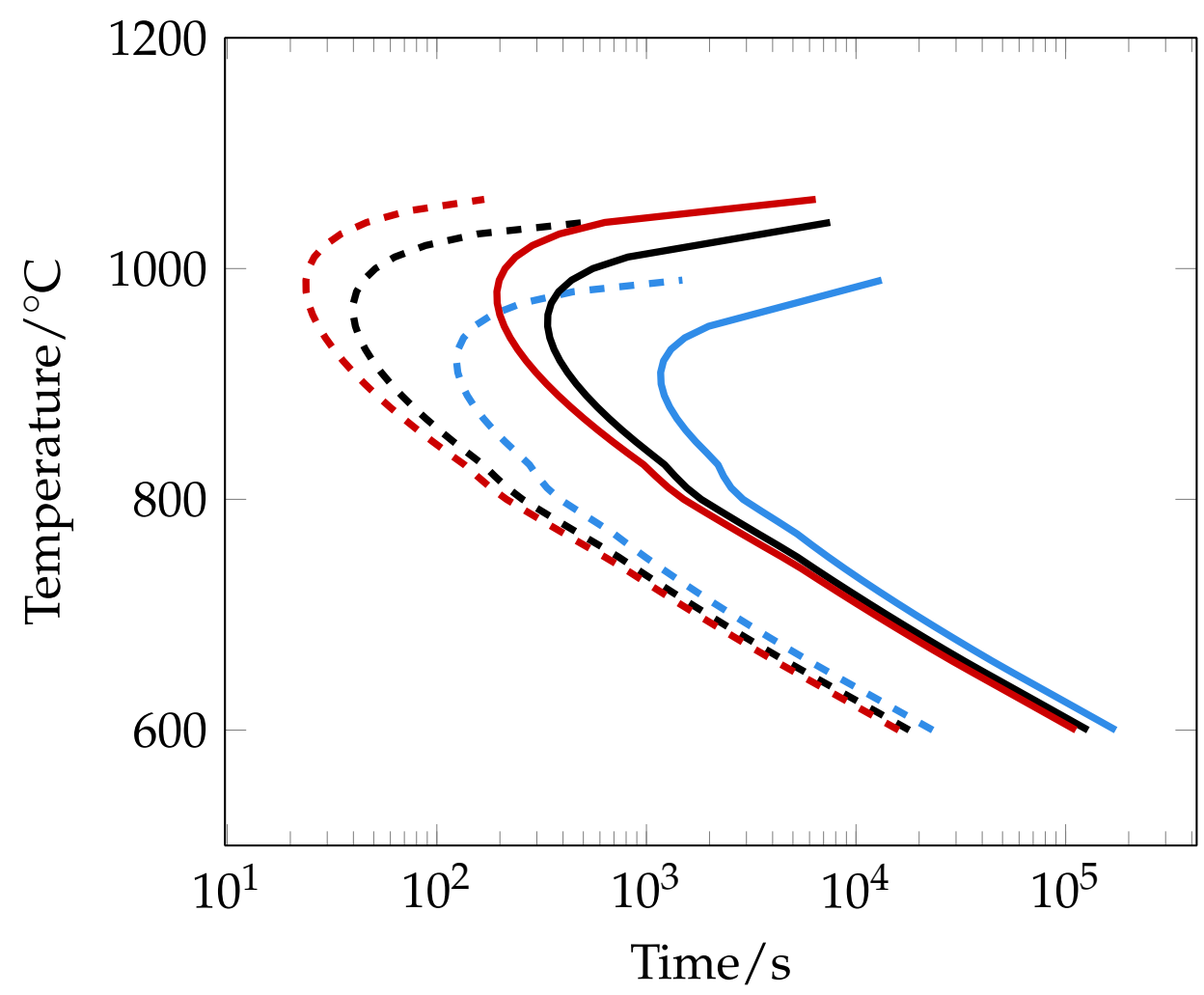

$$
\begin{aligned}
& -=0.1 \% 1000^{\circ} \mathrm{C}-1 \% 1000^{\circ} \mathrm{C} \\
& ---0.1 \% 1050{ }^{\circ} \mathrm{C}-1 \% 1050{ }^{\circ} \mathrm{C} \\
& ---0.1 \% 1100{ }^{\circ} \mathrm{C}-1 \% 1100{ }^{\circ} \mathrm{C}
\end{aligned}
$$

Figure 10. TTT $0.1 \%$ and $1 \%$ amount transformed (stainless steel mode: Austenitic) calculated by JMatPro ${ }^{\circledR}$ used for FEM. Transformation data of $\mathrm{M}_{23} \mathrm{C}_{6}$ is shown.

3.2. Experimental and Simulative Temperature Development during the Jominy End Quench Test of X30Cr13

Figure 11 shows the experimentally determined time-temperature curves of the thermocouples $T 1$ and T2, whose positions are shown in Figure 4. Simulated time-temperature curves match very well with the experimental ones during cooling, see Figures 12 and 13 . The correlation coefficient is 0.9983 . This confirms the good agreement. Please note that due to the test setup using thermocouples, the holding time $t_{m}$ between removal from the furnace and water quenching in the test device lasted more than $5 \mathrm{~s}$ (approximately between $8 \mathrm{~s}$ to $20 \mathrm{~s}$ ), see Figure 12. This is in deviation from EN ISO 642 [16] and explains why the cooling rate in the first few seconds is lowered. This deviation was taken into account in the simulation. 

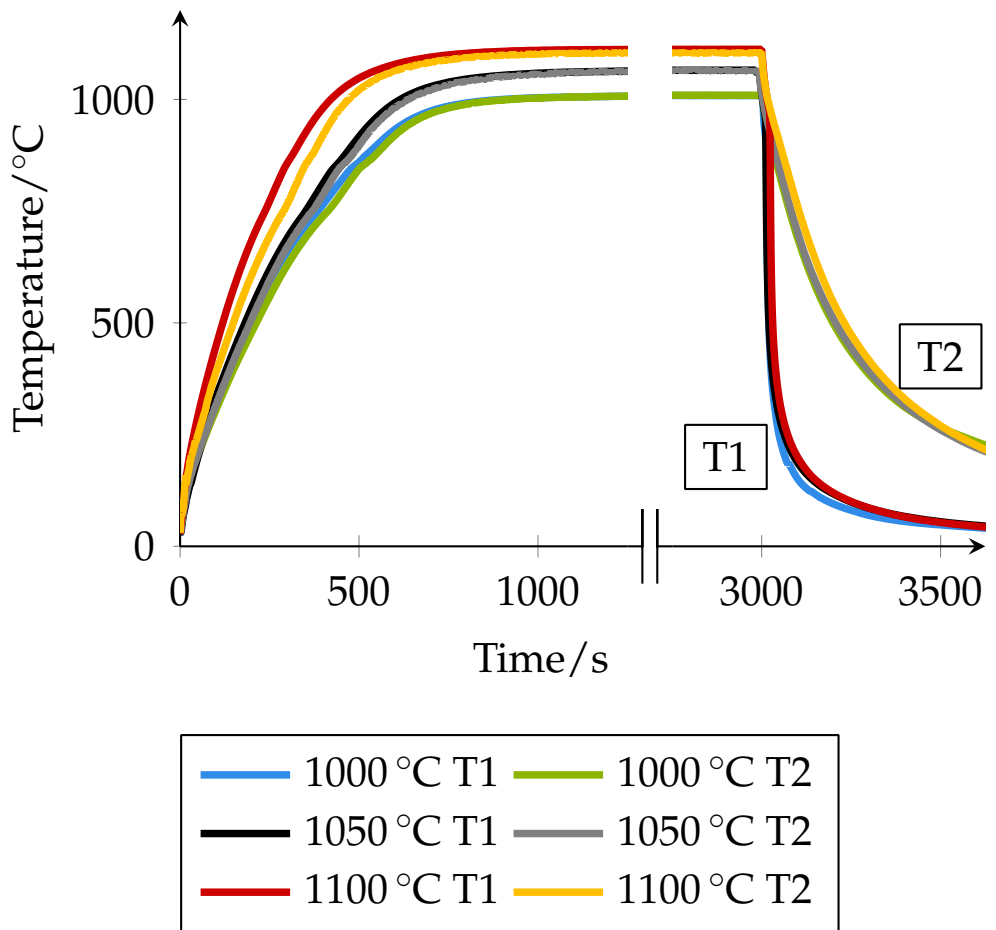

Figure 11. Experimental time-temperature sequences during the Jominy end quench test for different austenitizing temperatures.

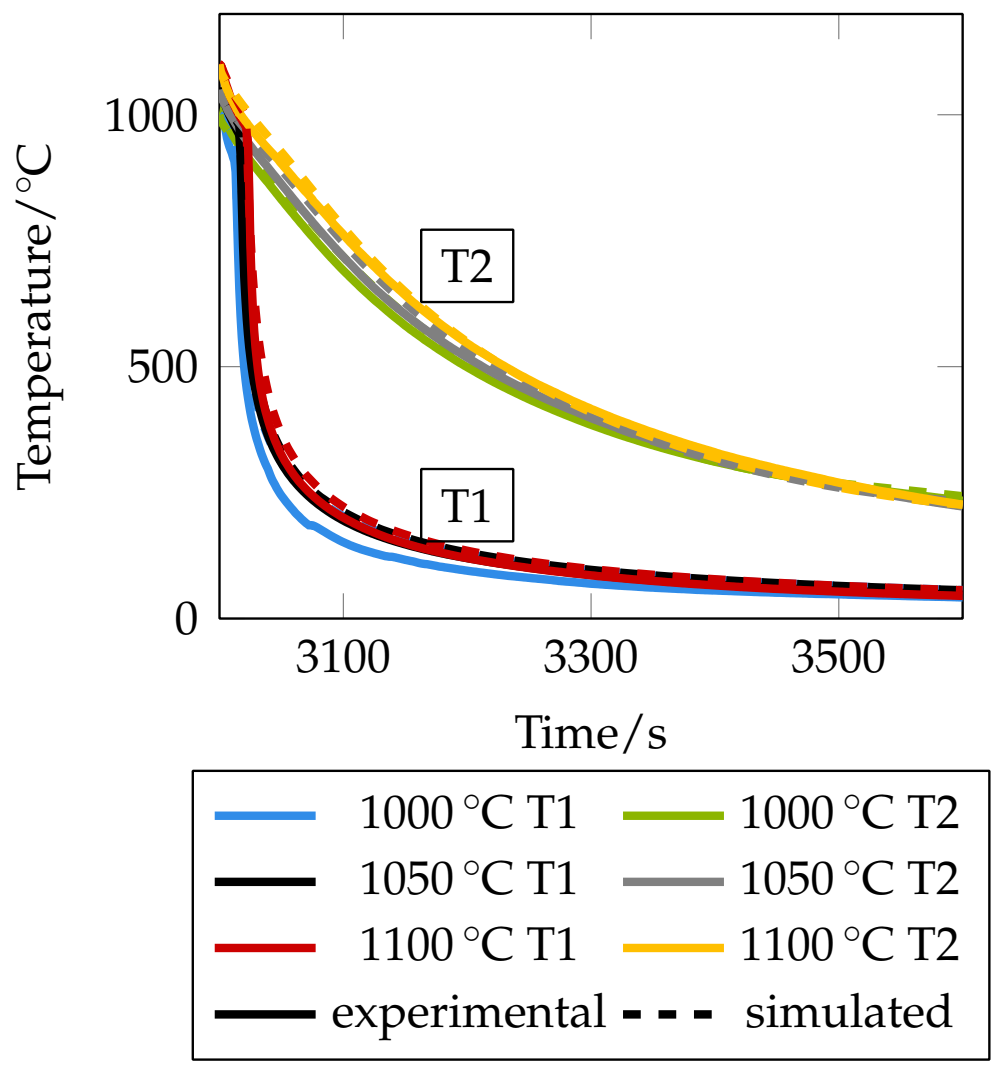

Figure 12. Comparison between experimental and simulated time-temperature sequences T1 and T2. 


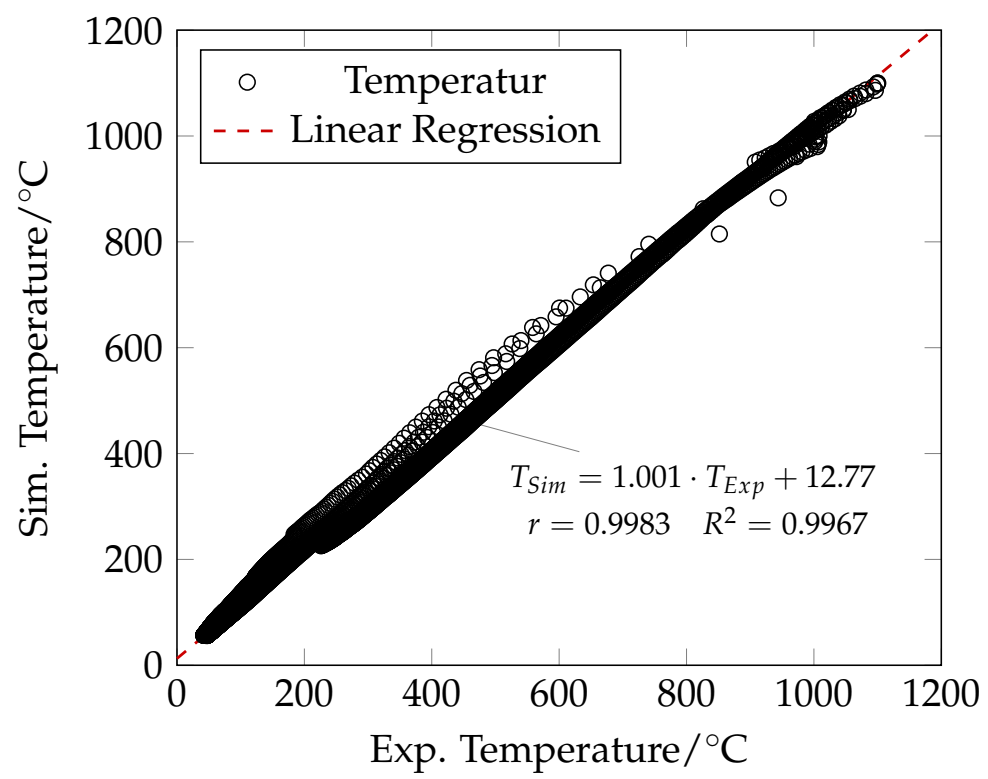

Figure 13. Correlation between experimental and simulated time-temperature curves.

Based on the measured cooling curves, the cooling rate $\dot{T}$ for each location at the Jominy end quench sample can be calculated by FE simulation. The cooling rate $\dot{T}$ is determined by averaging the cooling rate between $800^{\circ} \mathrm{C}$ and $500{ }^{\circ} \mathrm{C}$. In the field of high-alloy steels, it is also useful to use the $t_{10 / 7}$-time to determine the cooling rate, due to precipitation in the range from $1000^{\circ} \mathrm{C}$ to $700{ }^{\circ} \mathrm{C}$ [21]. As the removal of the face quench specimens from the furnace to the placement of the specimens in the Jominy end quench device takes some time, the cooling rate $t_{10 / 7}$ would include cooling in air, especially at the austenitizing temperature $\vartheta_{\mathrm{A}}$ of $1000^{\circ} \mathrm{C}$. For this reason, the $t_{8 / 5}$ time was used to calculate the cooling rates. Test surfaces of the specimens, each with a depth of approximately $0.4 \mathrm{~mm}$ to $0.5 \mathrm{~mm}$ starting from the surface $(12.5 \mathrm{~mm})$, were produced by grinding and polishing. Therefore, the cooling rate $\dot{T}$ as a function of the distance from the quenched end face from $Y=0 \mathrm{~mm}$ to $100 \mathrm{~mm}$ along the $X$ axis $=12 \mathrm{~mm}$ is shown in Figure 14 .

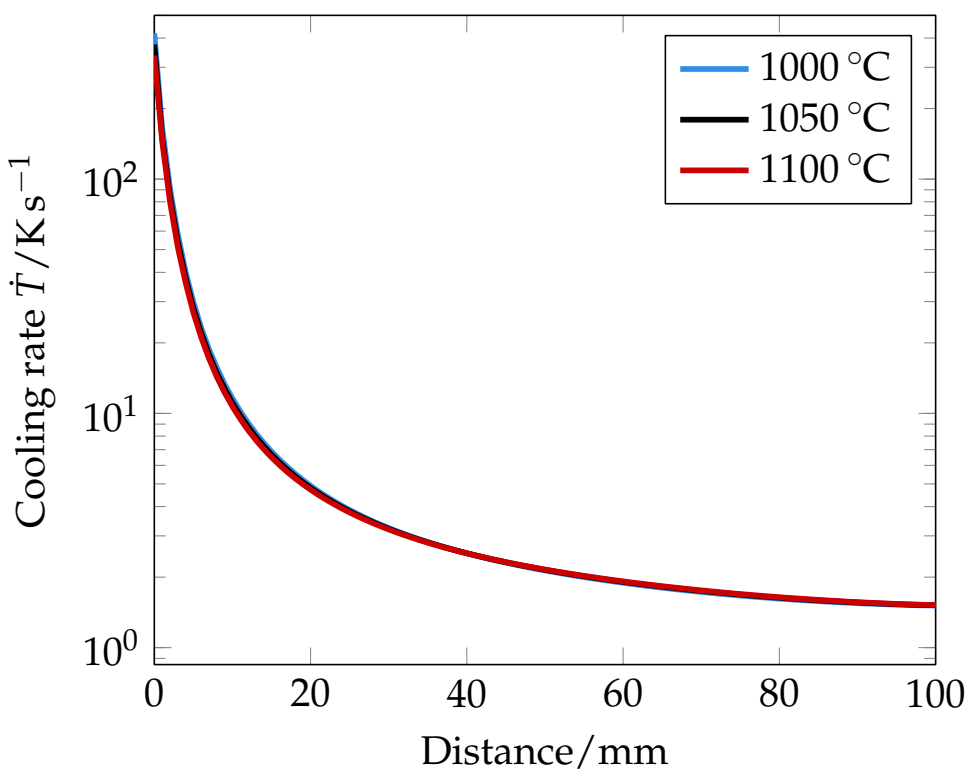

Figure 14. Cooling rate $\dot{T}$ calculated by FE simulation as a function of the distance (along the $X$ axis equal to $12 \mathrm{~mm}$ from $Y=0 \mathrm{~mm}$ to $Y=100 \mathrm{~mm}$ ). 


\subsection{Hardness, Pitting Corrosion Potential, and Microstructures of X30Cr13 Samples after Jominy} End Quench Test

Figures 15-17 show exemplary micrographs (optical microscopy and SEM) of X30Cr13 as a function of the austenitizing temperature and distance from the quenched end face of the bar, i.e., at different cooling rates. It can be seen that with increasing austenitizing temperature the number of carbides decreases and the grain size increases. In Figure 16, the retained austenite is very well recognizable. The correlation that the proportion of carbides in the quenched microstructure decreases when the temperature increases at a constant heating rate and holding time was also observed in $[8,9]$. The grain sizes determined according to [18] are listed in Table 6. The results confirm the statements made in the literature $[5,9]$ that the grain size increases due to diffusion with increasing proportions of carbides dissolved in the austenite. Strong grain growth is observed at $1100^{\circ} \mathrm{C}$, evidencing the argument that the carbides are almost completely dissolved in the austenite at this temperature. By comparing the microstructures at different distances from the front surface, the influence of the cooling rate is illustrated. The amount of precipitated carbides increases with increasing distance to the front surface and thus decreasing cooling rate. The influence of the cooling rate is also described in [8,9] and confirms the observations made here. Furthermore, it can be seen that grain boundary carbides seem to become more developed with increasing distance and thus with decreasing cooling rate. Therefore, it can be concluded that carbides are precipitated preferentially at the grain boundaries during cooling. In addition, carbides can also form in the grain interior during cooling, compare Figure 17.

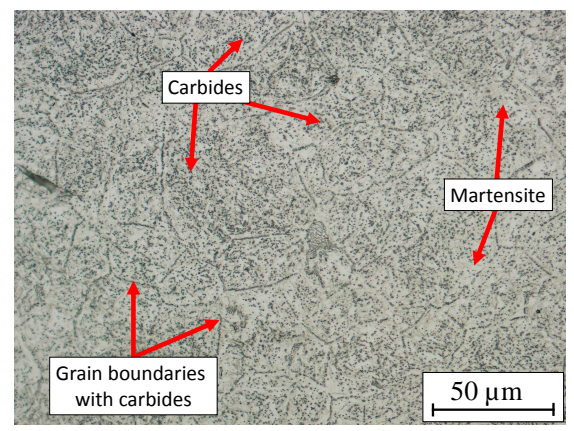

(a) $1000^{\circ} \mathrm{C}$ and $1 \mathrm{~mm}$

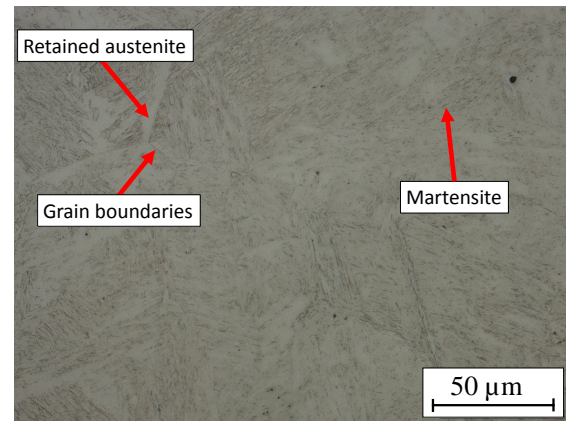

(c) $1100{ }^{\circ} \mathrm{C}$ and $1 \mathrm{~mm}$

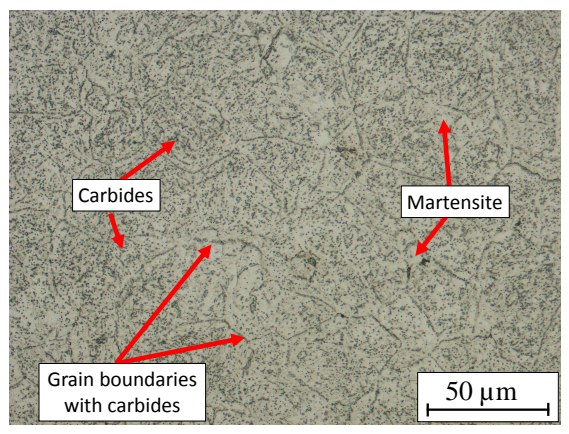

(b) $1000^{\circ} \mathrm{C}$ and $50 \mathrm{~mm}$

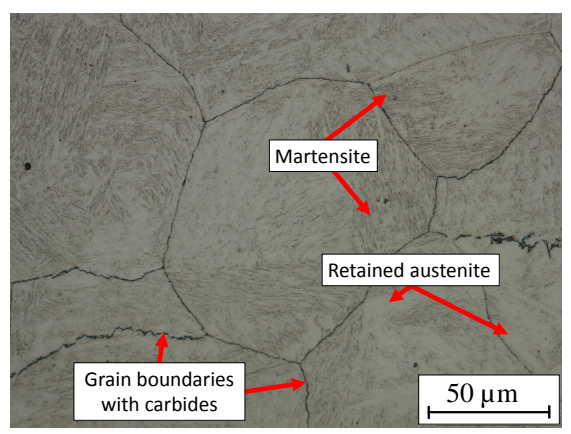

(d) $1100^{\circ} \mathrm{C}$ and $50 \mathrm{~mm}$

Figure 15. Selected micrographs (optical microscopy) of $\mathrm{X} 30 \mathrm{Cr} 13$ as a function of the austenitizing temperature and the distance from the quenched end face and thus the cooling rate: (a) $1000^{\circ} \mathrm{C}$ and $1 \mathrm{~mm}$, (b) $1000^{\circ} \mathrm{C}$ and $50 \mathrm{~mm}$, (c) $1100^{\circ} \mathrm{C}$ and $1 \mathrm{~mm}$, and (d) $1100^{\circ} \mathrm{C}$ and $50 \mathrm{~mm}$. V2A reagent was used as the etchant.

The results of the EDX measurements, see Table 7 and Figure 18, indicate that the carbides (chromium carbides) have a significantly higher chromium fraction than the matrix (martensite and possibly small amounts of retained austenite). When measuring the chromium contents of small carbides in particular, it cannot be excluded that matrix 
contents are also detected. This must be taken into account when interpreting the results. Assuming the mixing rule, Equations (1)-(3), it becomes clear that the higher the volume fraction of chromium carbides $\left(\xi_{\text {Carbide }}\right)$, the more the chromium content in the matrix $\left(c_{\text {Matrix }}^{C r}\right)$ decreases, compare Figure 6. In Equation (1), $\xi_{i}$ are the volume fraction of i-phase and $c_{i}^{C r}$ is the chromium content of i-phase. The i-phase represents either the carbides or the matrix (martensites and retained austenite). If carbides form during cooling, the decrease in the chromium content of the matrix is locally limited due to the short cooling times and thus short diffusion times and paths. The local chromium depletion is described in more detail in $[2,3]$.

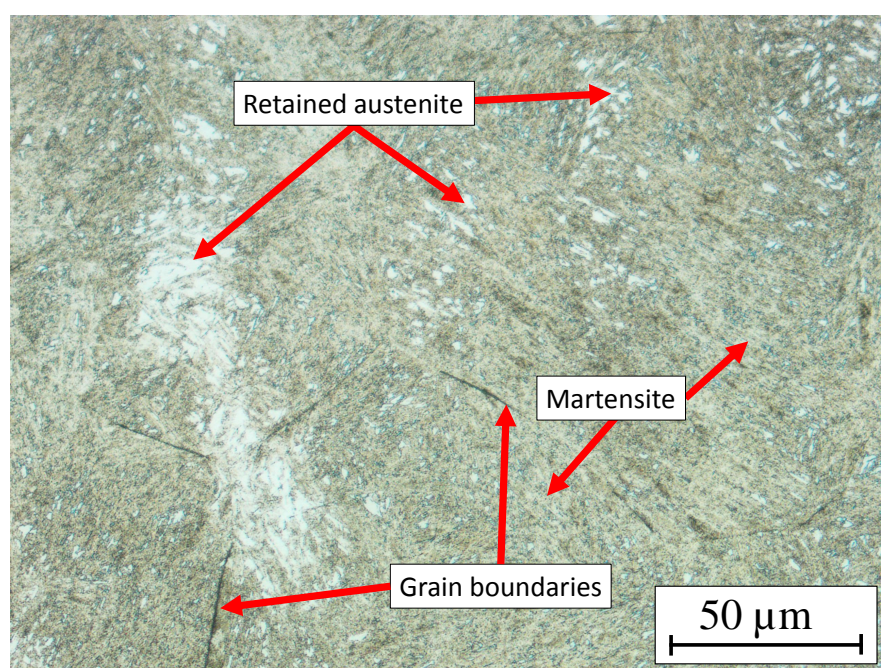

Figure 16. Selected micrographs (optical microscopy) of $\mathrm{X} 30 \mathrm{Cr} 13$ of $1100{ }^{\circ} \mathrm{C}$ and $1 \mathrm{~mm}$ distance from the quenched end face using an etchant accoding to the work in [17] consisting of $925 \mathrm{~mL}$ ethanol, $25 \mathrm{~g}$ picric acid, and $50 \mathrm{~mL}$ hydrochloric acid. The retained austenite is very well recognizable.

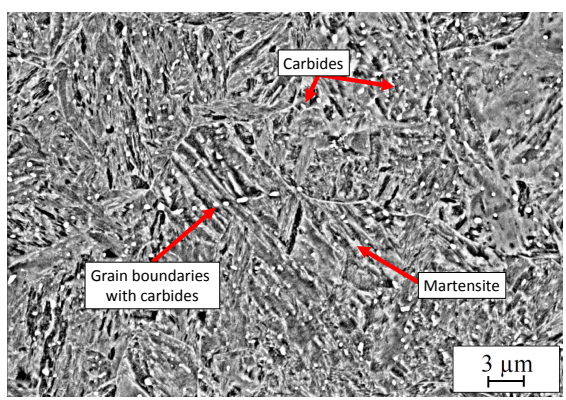

(a) $1000{ }^{\circ} \mathrm{C}$ and $1 \mathrm{~mm}$

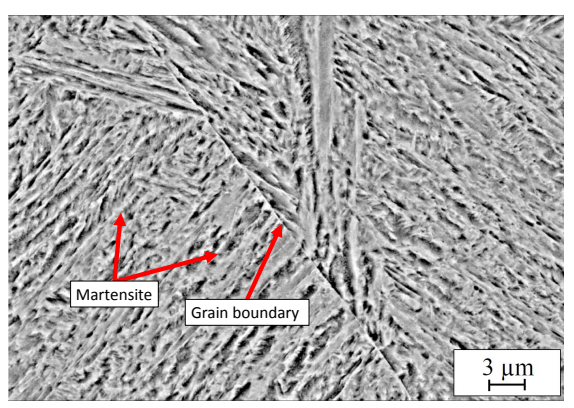

(c) $1100^{\circ} \mathrm{C}$ and $1 \mathrm{~mm}$

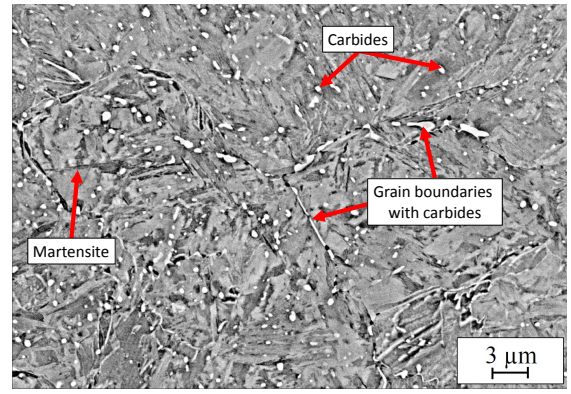

(b) $1000^{\circ} \mathrm{C}$ and $50 \mathrm{~mm}$

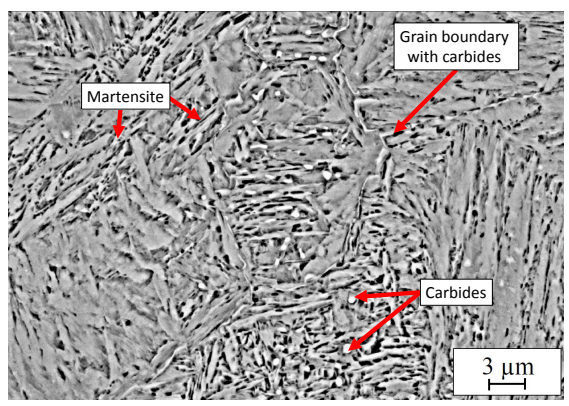

(d) $1100^{\circ} \mathrm{C}$ and $50 \mathrm{~mm}$

Figure 17. Selected micrographs (SEM: EHT $=20 \mathrm{kV}$, Detector $=\mathrm{HDBSD}, \mathrm{WD}=6.2 \mathrm{~mm}$ to $7.5 \mathrm{~mm}$ ) of $\mathrm{X} 30 \mathrm{Cr} 13$ as a function of the austenitizing temperature and the distance from the quenched end face and thus the cooling rate: (a) $1000^{\circ} \mathrm{C}$ and $1 \mathrm{~mm}$, (b) $1000^{\circ} \mathrm{C}$ and $50 \mathrm{~mm}$, (c) $1100{ }^{\circ} \mathrm{C}$ and $1 \mathrm{~mm}$, and (d) $1100^{\circ} \mathrm{C}$ and $50 \mathrm{~mm}$. 
Table 6. Determined grain size G according to the work in [18] as a function of austenitizing temperatures in ${ }^{\circ} \mathrm{C}$. The holding time including heating was $50 \mathrm{~min}$.

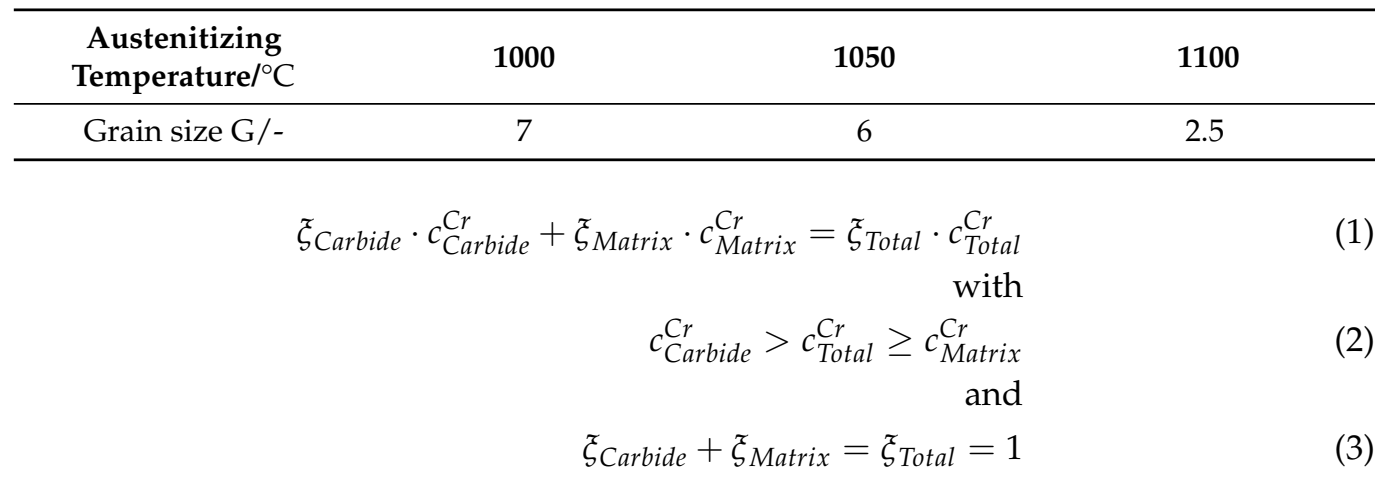

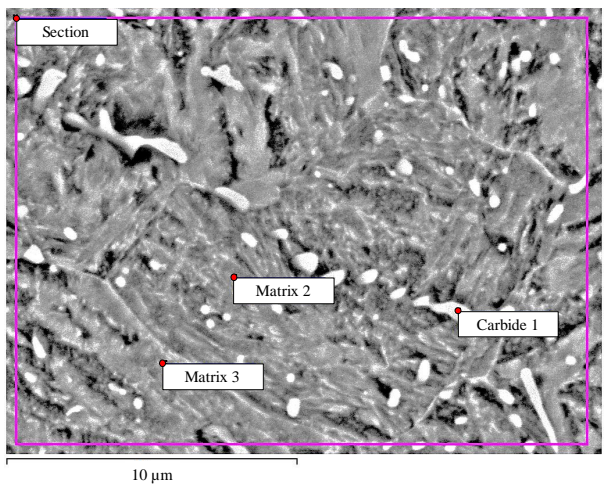

(a) $1000^{\circ} \mathrm{C}$ and $1 \mathrm{~mm}$

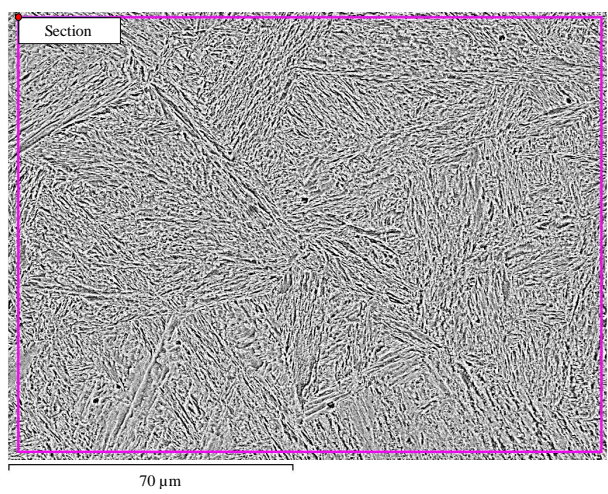

(c) $1100{ }^{\circ} \mathrm{C}$ and $1 \mathrm{~mm}$

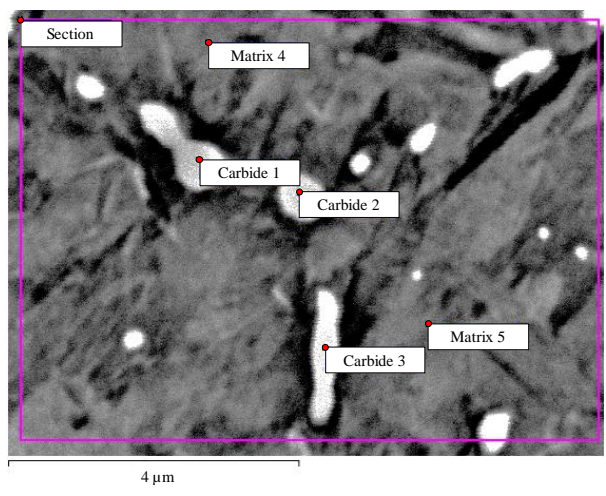

(b) $1000^{\circ} \mathrm{C}$ and $50 \mathrm{~mm}$

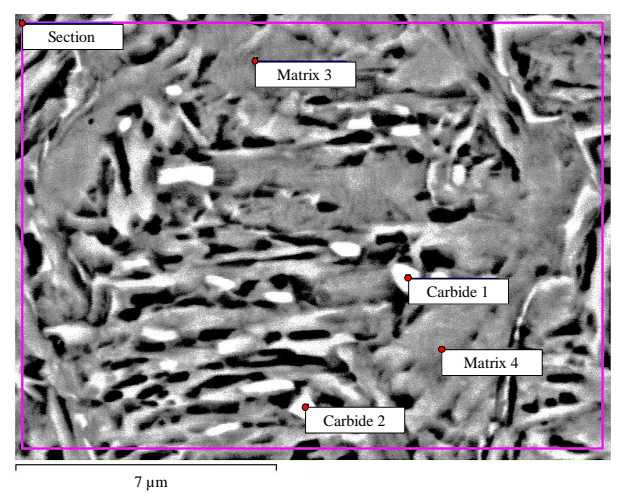

(d) $1100{ }^{\circ} \mathrm{C}$ and $50 \mathrm{~mm}$

Figure 18. Selected microstructures of $\mathrm{X} 30 \mathrm{Cr} 13$ used for EDX analysis with SEM as a function of the austenitizing temperature and the distance from the quenched end face and thus the cooling rate: (a) $1000^{\circ} \mathrm{C}$ and $1 \mathrm{~mm},(\mathbf{b}) 1000^{\circ} \mathrm{C}$ and $50 \mathrm{~mm}$, (c) $1100^{\circ} \mathrm{C}$ and $1 \mathrm{~mm}$, and (d) $1100^{\circ} \mathrm{C}$ and $50 \mathrm{~mm}$. The different measuring points are marked and named. The analyzed sections are framed in pink.

The pattern measured by XRD of the different Jominy end quench test specimens with varying austenitizing temperature and distance from the quenched end face, and thus different cooling rate $\dot{T}$, are shown in Figure 19. 
Table 7. Mass fraction of chromium in \% measured by EDX Analysis using SEM. In addition to the chromium content, the content of silicon, sulfur, manganese, and iron was determined. The mass fractions of carbon were not considered in the quantification because the atomic number of carbon is only six. At $1100{ }^{\circ} \mathrm{C}$ and $1 \mathrm{~mm}$, no chromium content of the carbides could be determined because no carbides were recognizable or they were too small. Therefore, a larger section is analyzed. This is assumed to be the matrix (mainly martensite with small fractions of retained austenite). Please note that the analyzed sections cover different areas/volumes, each with different fractions of carbides, compare Figure 18 (pink frame).

\begin{tabular}{|c|c|c|c|c|c|c|c|c|}
\hline \multirow{2}{*}{$\begin{array}{l}\text { Temperature } /{ }^{\circ} \mathrm{C} \\
\text { Measuring } \\
\text { fields }\end{array}$} & \multirow[t]{2}{*}{ Distance/mm } & \multicolumn{3}{|c|}{ Carbides } & \multicolumn{2}{|c|}{$\begin{array}{c}\text { Matrix } \\
\text { (Martensite) }\end{array}$} & \multicolumn{2}{|c|}{ Section } \\
\hline & & 1 & 2 & 3 & 1 & 2 & 1 & 2 \\
\hline 1000 & 1 & 31.57 & & & 14.18 & 13.61 & & 14.94 \\
\hline 1000 & 50 & 36.51 & 33.80 & 24.86 & 13.35 & 12.81 & 14.62 & 14.28 \\
\hline 1100 & 1 & & & & & & 14.10 & 13.95 \\
\hline 1100 & 50 & 21.99 & 35.93 & & 15.72 & 15.06 & & 16.72 \\
\hline
\end{tabular}

Table 8 summarizes the resulting mass fractions of the martensite and retained austenite phases of the Jominy end quench specimens treated at different austenitizing temperatures at distances of $1 \mathrm{~mm}$ and $50 \mathrm{~mm}$ from the quenched end face, determined by XRD. The mass fraction of the retained austenite is plotted in Figure 20. It can be seen that at $1100{ }^{\circ} \mathrm{C}$ on average approximately $17-20 \%$ retained austenite is present. When analyzing the phase fractions, fluctuating results were observed for the Jominy end quench test specimens, which were austenitized at $1100^{\circ} \mathrm{C}$. Thus, eight XRD measurements were performed on each of the specimen austenitized at $1100^{\circ} \mathrm{C}$ at different distances from the quenched end face of $1 \mathrm{~mm}$ and $50 \mathrm{~mm}$. The reasons for these variations can be due to the fact that with a small collimator $(0.5 \mathrm{~mm})$ and large grains, too few grains may be recorded to fulfill the Bragg condition and for this reason the retained austenite contents may vary greatly. Furthermore, inhomogeneities in the local chemical composition could also lead to strongly varying retained austenite contents. At $1050^{\circ} \mathrm{C}$ and at a distance of $1 \mathrm{~mm}$ from the quenched end face, the retained austenite value is in the range of 2.5 to $6 \%$. At $1050{ }^{\circ} \mathrm{C}$ and $50 \mathrm{~mm}$ distance to the quenched end face, as well as at $1000^{\circ} \mathrm{C}$, the retained austenite content is in the range of $<1 \%$ to $4 \%$. It can be seen that as the austenitizing temperature increases, the retained austenite content increases.

The c/a ratio with the respective minimum and maximum values is shown in Figure 21 to illustrate the scatter range. An increase in the $\mathrm{c} / \mathrm{a}$ ratio indicates a higher tetragonality and thus a higher carbon content of the martensite. The $c / a$ ratio should increase with higher austenitizing temperature as more chromium carbides are dissolved in the austenite, see Figure 6 and Table 4. The evaluation of the $c / a$ ratios measured by XRD suggests this trend, but the scatter band, based on the respective Minimum and Maximum values of the measurements, does not allow a clear statement. The differences of the carbon contents and thus of the c/a ratio are apparently too small, so that they lie within the scatter of the measured values. According to the thermodynamic calculations using JMatPro ${ }^{\circledR}$, the carbon content varies between $0.24 \%$ at $1000^{\circ} \mathrm{C}$ and $0.37 \%$ at $1100{ }^{\circ} \mathrm{C}$. A comparison with the works in $[22,23]$ shows that the determined values of the $\mathrm{c} /$ a ratio are in the correct order of magnitude. A slight increase in the $\mathrm{c} /$ a ratio can be seen on average, particularly from $1000^{\circ} \mathrm{C}$ to $1100^{\circ} \mathrm{C}$ at $50 \mathrm{~mm}$ distance to the quenched end face. At the distance of $1 \mathrm{~mm}$ of the quenched end face, a slight increase in the c/a ratio from $1000^{\circ} \mathrm{C}$ to $1050^{\circ} \mathrm{C}$ can also be observed. However, the $\mathrm{c} / \mathrm{a}$ ratio drops again slightly on average at $1100^{\circ} \mathrm{C}$. The slight drop in the $\mathrm{c} / \mathrm{a}$ ratio at $1100^{\circ} \mathrm{C}$ and $1 \mathrm{~mm}$ distance to the quenched end face may indicate slight decarburization, which may not have been avoided despite heat treatment in inert gas. The expected c/a ratio change due to slower cooling is within the fluctuations (scatter band), so that no definite statements can be made. 


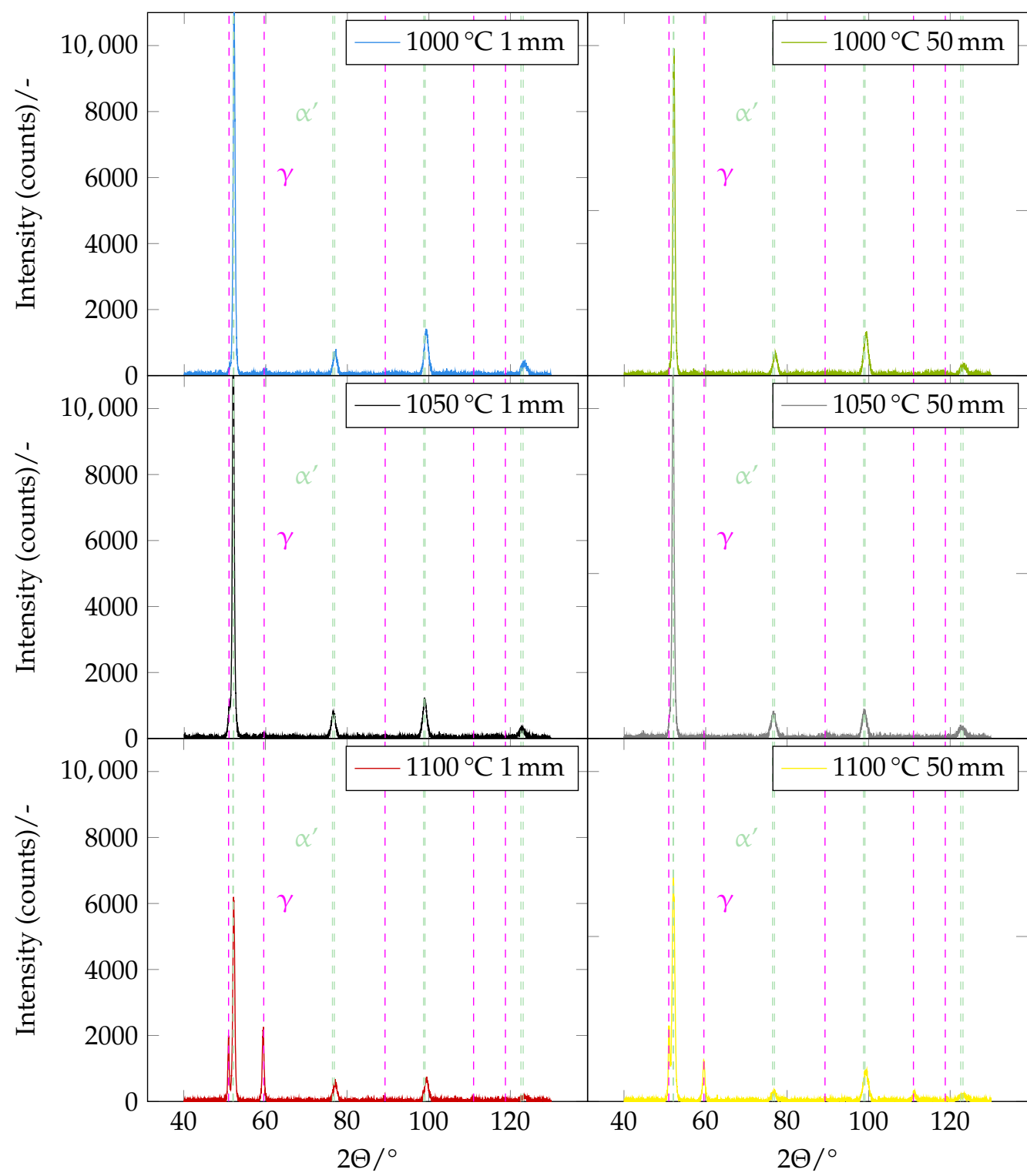

Figure 19. XRD pattern of the different Jominy end quench test specimens at different austenitizing temperature and distance from the quenched end face. The counts are plotted as a function of the angle $2 \Theta$. The postion of the phases austenite and martensite are marked.

Table 8. Mass fractions of retained austenite and martensite phases of the Jominy end quench test specimens as a function of austenitizing temperature and distance from the quenched end face measured by XRD. Note that a quantification of the fractions of chromium carbides based on the XRD investigations was not possible due to their too low contents and densities. At $1050^{\circ} \mathrm{C}$ and $50 \mathrm{~mm}$ distance to the quenched end face, as well as at $1000^{\circ} \mathrm{C}$, the retained austenite content was in the first measurement below the detection limit of $1 \%$. The standard deviation of the phase fractions for the samples austenitised at $1100^{\circ} \mathrm{C}$ results from the eight measurements.

\begin{tabular}{lccc}
\hline Temperature $/{ }^{\circ} \mathrm{C}$ & $\mathbf{1 0 0 0}$ & $\mathbf{1 0 5 0}$ & $\mathbf{1 1 0 0}$ \\
\hline Distance $/ \mathrm{mm}$ & Mass fraction & of retained austenite $/ \%$ \\
1 & $<1-4$ & $2-6$ & $17 \pm 9$ \\
50 & $<1-2$ & $<1-3$ & $20 \pm 14$ \\
Distance $/ \mathrm{mm}$ & \multicolumn{2}{c}{ Mass } & fraction of \\
1 & $96->99$ & $94-98$ & $83 \pm 9$ \\
50 & $98->99$ & $97->99$ & $80 \pm 14$ \\
\hline
\end{tabular}




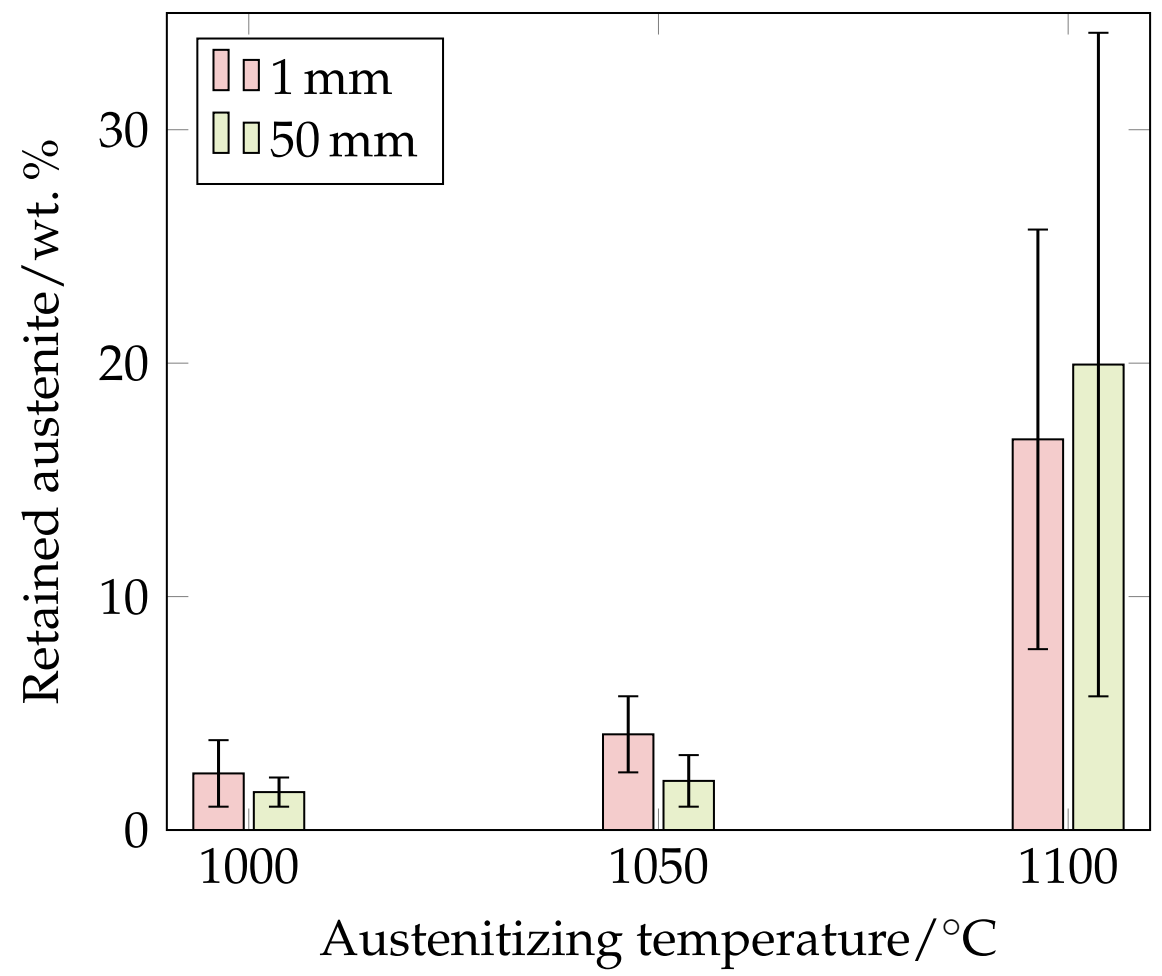

Figure 20. Retained austenite measured by XRD. At $1000^{\circ} \mathrm{C}$ and $1050^{\circ} \mathrm{C}$ the mean values are shown with the respective minimum and maximum values. Note that a mass fraction of $1 \%$ is the detection limit. Due to larger variations at $1100^{\circ} \mathrm{C}$, a total of eight measurements, each at $1 \mathrm{~mm}$ and $50 \mathrm{~mm}$, were carried out by XRD. In this case, the mean values and the standard deviation are presented.

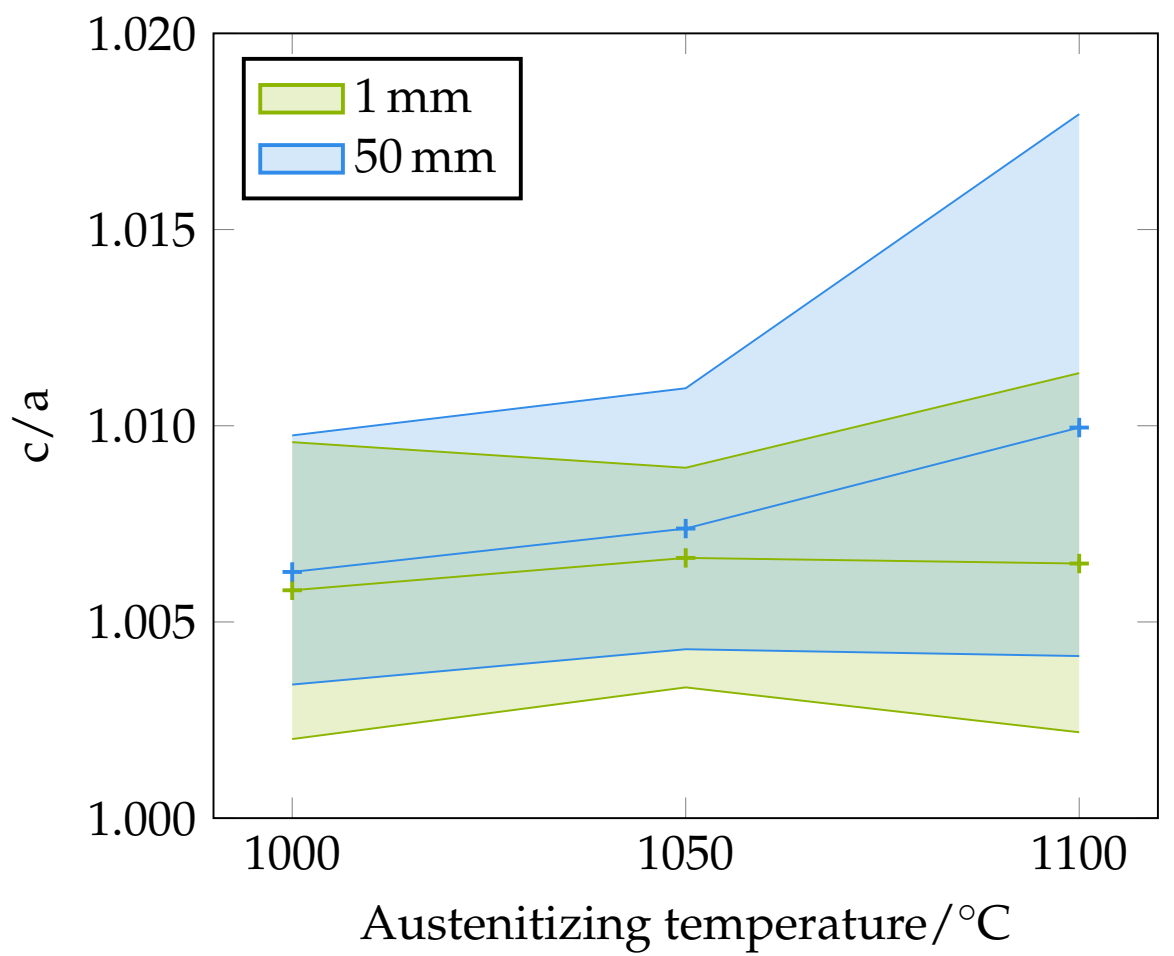

Figure 21. $\mathrm{c} / \mathrm{a}$ ratio of martensite with respective scattering band (minimum and maximum) measured by XRD. 
The profiles of the resulting hardness values determined experimentally along the sample as a function of the distance from the quenched end faces of the Jominy end quench samples are shown in Figure 22 for the hardness measured in HV10. There are several influences on the hardness. The hardness is influenced due to the variation of the carbon content in the solid solution, the fraction of retained austenite and the grain size (HallPetch effect). Neglecting the grain size, the hardness can be described by the following Equations (4) and (5):

$$
\begin{array}{r}
H_{\text {local }}=H_{M}(C) \cdot \xi_{M}+H_{A}(C) \cdot \xi_{A}+H_{\text {Carbide }} \cdot \xi_{\text {Carbide }} \\
\text { and } \\
\xi_{M}+\xi_{A}+\xi_{\text {Carbide }}=\xi_{\text {Total }}=1
\end{array}
$$

$H_{\text {local }}$ is the local hardness, $H_{i}(\mathrm{C})$ is the hardness of i-phase in dependency of the carbon content $(\mathrm{C})$, and $\xi_{i}$ is the volume fraction of $\mathrm{i}$-phase. The $\mathrm{i}$-phase denotes the martensite $(\mathrm{M})$, retained austenite (A), or carbides (Carbide). According to García de Andrés [5], a retained austenite content of more than $10 \%$ by volume significantly reduces the yield strength and hardness. The thermodynamic calculations, see Figure 6 and Table 4, show an increase of the alloying elements content, especially carbon and chromium, dissolve in the austenite with increasing austenitizing temperature. Thus, the proportion of retained austenite increases after quenching, as shown by the XRD studies, see Figure 20 and Table 8. The c/a ratio increases slightly with increasing austenitizing temperature, i.e., the carbon content increases and thus the hardness of the martensite. However, since the retained austenite content also increases, the hardness decreases in total, based on Equations (4) and (5).

The influences described are confirmed in the hardness curves obtained, see Figure 22. It can be seen that the austenitizing temperature exerts a major influence on the hardness curves. The scatter of hardness is larger up to approximately $5 \mathrm{~mm}$ distance from the quenched end face compared to the scatter of hardness of the rest of the specimen. A drop in hardness has occurred at the higher austenitizing temperatures, which can be attributed to higher content of retained austenite. Otherwise, the hardness remains relatively constant over the entire sample length. As the distance to the quenched end face increases, the cooling rate decreases and chromium carbides can form. The influence of the precipitated carbides during slow cooling on the hardness seems to be less than the influence of the austenitizing temperature. At an austenitizing temperature of $1000^{\circ} \mathrm{C}$, a slight drop in hardness can be observed as a function of distance from the quenched end face. These observations are also confirmed in the Figure 23.

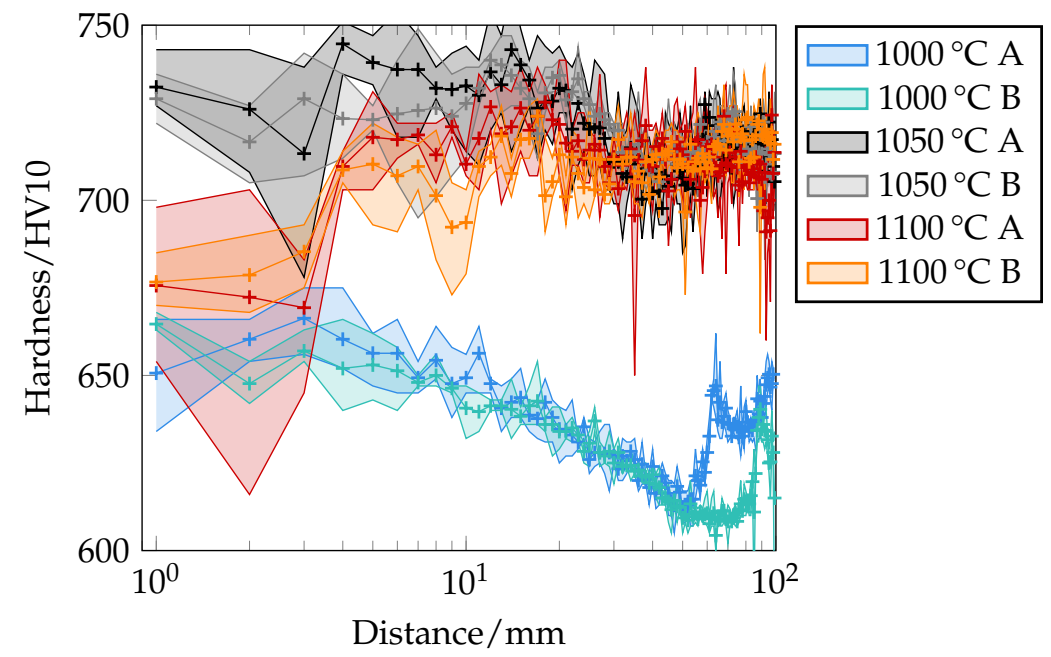

Figure 22. Experimentally determined hardness profile as a function of the distance from the quenched end face of the Jominy end quench test in HV10. Measured every $1 \mathrm{~mm}$ indicated by marks $(+)$. A and B indicate the respective test area of different specimens. 


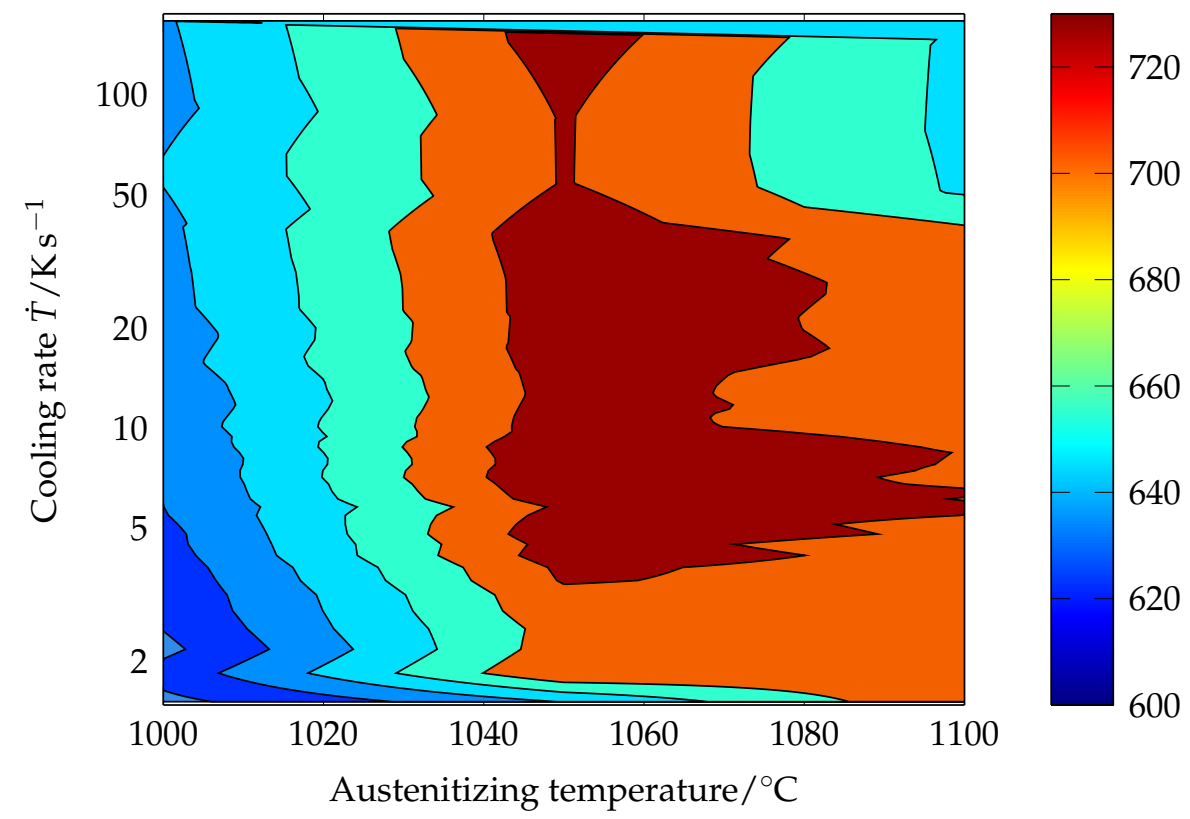

Figure 23. Hardness/HV10 as a function of the cooling rate (logarithmic scale) and the austenitizing temperature.

The pitting corrosion potentials are shown in Table 9 and Figure 24. Figure 24 shows the pitting corrosion potentials, which have been determined from average values of between 3 and 5 data, and the respective minimum and maximum measured values as a function of the distance from the quenched end face. It can be clearly seen that there are large fluctuations between the minimum and maximum values. These can occur due to inhomogeneities in the microstructure, which lead to variations in the pitting potential due to the limited examination areas in the applied microcorrosion measurements. Immediately at first occurrence of the pitting potential, all measurement procedures were interrupted (brake-off criterion) in order to avoid further damage. This allows to evaluate the damage pattern before the start of severe corrosion after the breakdown of the passive layer. However, a preferred pitting corrosion in the edge area is not directly evident in the initial, small damages, but become visible when existing pits continue to grow. Thus, deviations of the measured potentials due to incipient marginal corrosion can occur and cannot be avoided by the applied test setup.

Table 9. Pitting corrosion potentials $\mathrm{Ag} / \mathrm{AgCl}(3 \mathrm{~mol} \mathrm{KCl}) / \mathrm{mV}$.

\begin{tabular}{lccc}
\hline Temperature $/{ }^{\circ} \mathrm{C}$ & $\mathbf{1 0 0 0}$ & $\mathbf{1 0 5 0}$ & $\mathbf{1 1 0 0}$ \\
\hline $\begin{array}{l}\text { Distance } / \mathrm{mm} \\
1\end{array}$ & Pitting corrosion & potentials $/ \mathrm{mV}$ & \\
2.5 & $680_{-154}^{+205}$ & $685_{-224}^{+241}$ & $1093_{-307}^{+262}$ \\
5 & $783_{-398}^{+218}$ & $730_{-213}^{+231}$ & $1020_{-538}^{+303}$ \\
10 & $574_{-14}^{+7}$ & $716_{-99}^{+149}$ & $1026_{-177}^{+344}$ \\
20 & $712_{-66}^{+64}$ & $914_{-130}^{+192}$ & $1112_{-112}^{+79}$ \\
50 & $679_{-214}^{+178}$ & $550_{-59}^{+74}$ & $960_{-415}^{+255}$ \\
80 & $562_{-69}^{+114}$ & $489_{-194}^{+128}$ & $507_{-180}^{+168}$ \\
\hline
\end{tabular}




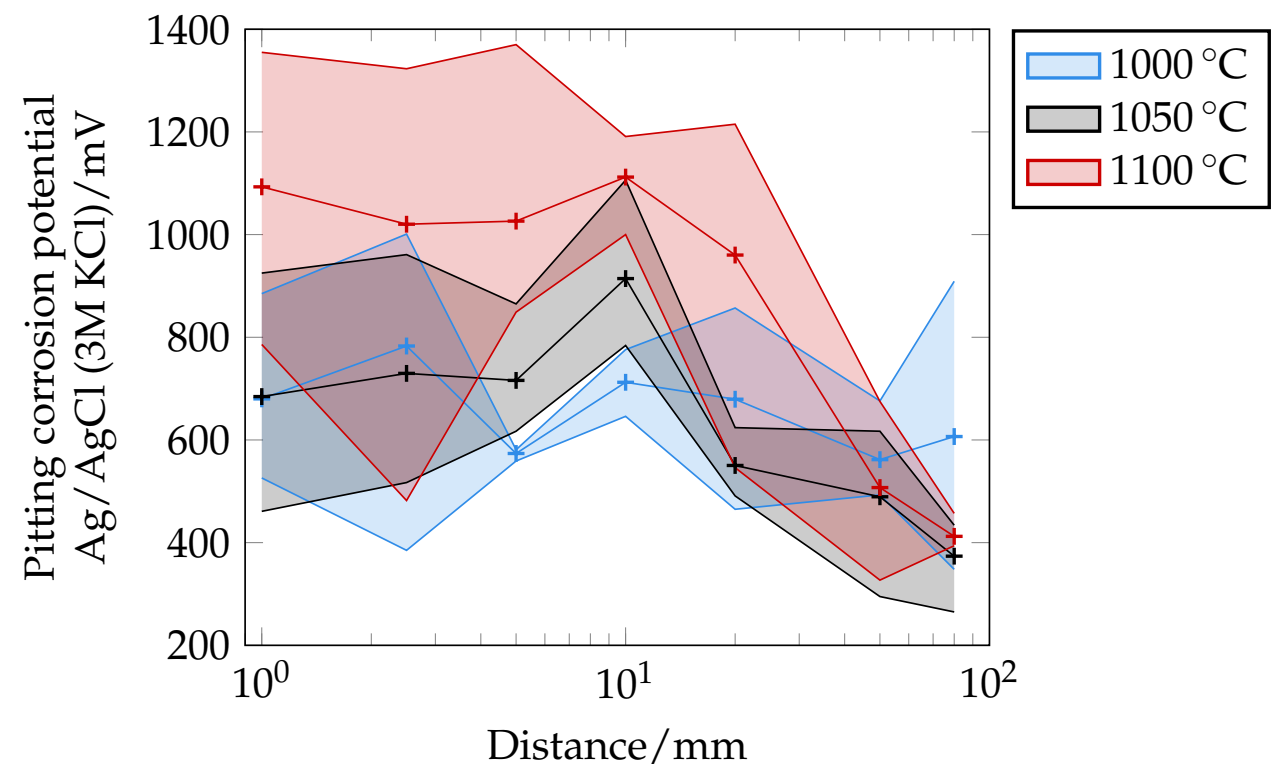

Figure 24. Experimentally determined pitting corrosion potential as a function of the distance from the quenched end face of the Jominy end quench test in $\mathrm{mV}$. Measuring points indicated by marks (+): $1 \mathrm{~mm}, 2.5 \mathrm{~mm}, 5 \mathrm{~mm}, 10 \mathrm{~mm}, 20 \mathrm{~mm}, 50 \mathrm{~mm}, 80 \mathrm{~mm}$.

Figures 23 and 25 show the hardness and pitting corrosion potentials as a function of the austenitizing temperature and cooling rate. In Figure 23, it is visible that the levels of hardness in HV10 reach their highest values when both austenitizing temperatures and cooling rates are high. The highest hardness is observed at $1050^{\circ} \mathrm{C}$. The decrease in hardness at the beginning of the quenching test is noticeable. This is probably due to too rapid cooling and resulting brittle behavior as well as hardening cracks. Note that the Jominy end quench test samples were not tempered after cooling. Similar to the HRC measurements, a drop in hardness is observed at the very high cooling rates. However, this is less pronounced. Compared to HRC measurements $(140 \mathrm{kP})$, the forces in the determination using HV10 (10 kP) are significantly lower, so that any cracks that may be present have less effect, as the diameter of the indentations is significantly smaller or fewer cracks form during the measurement due to the lower forces. The pitting corrosion potentials show a similar behavior. With an increase in austenitizing temperature in combination with high cooling rates, a better pitting corrosion resistance is present, see Figure 25. At the beginning of the sample, larger variations of the corrosion potentials are also visible and it is to be noted that at medium cooling rates a renewed increase in pitting corrosion resistance appears to have occurred. This may also be due to microscopic hardening cracks. Note that inhomogeneities that occur in the microstructure can also lead to strong fluctuations in the corrosion measurements, which are not necessarily due to metallurgical effects caused by the heat treatments. Further improvements of the applied corrosion test setup are necessary to minimize the fluctuations of the pitting corrosion potentials measurements and to assess the resulting secondary increase in pitting corrosion potential better.

The presented diagrams can be used to determine process windows for an adequate combination of hardness level and corrosion resistance in specific applications, as exemplified in Figure 26. To determine a suitable process window, the respective normalized hardness and the respective normalized pitting corrosion potential were multiplied together as a function of the cooling rate and the austenitizing temperature. The hardness and the corrosion potentials are thus equally weighted in the example shown. The hardness and the pitting corrosion potential were each normalized between zero and one as a function of the respective experimental minimum and maximum values. It can be seen that high hardness as well as pitting corrosion resistance is achieved at austenitizing temperatures above $1050{ }^{\circ} \mathrm{C}$ and cooling rate between $5 \mathrm{~K} \mathrm{~s}^{-1}$ to $40 \mathrm{~K} \mathrm{~s}^{-1}$. At a cooling rate of approxi- 
mately $10 \mathrm{~K} \mathrm{~s}^{-1}$, the combined properties show relatively constant high values over a wide temperature range $\left(1050^{\circ} \mathrm{C}\right.$ to $\left.1100^{\circ} \mathrm{C}\right)$ and at an austenitizing temperature of $1100^{\circ} \mathrm{C}$ the hardness and corrosion resistance are consistently higher over the widest range of cooling rates $\left(5 \mathrm{~K} \mathrm{~s}^{-1}\right.$ to $\left.40 \mathrm{~K} \mathrm{~s}^{-1}\right)$ compared to other austenitizing temperatures. This is indicated in yellow and green color in the Figure 26.

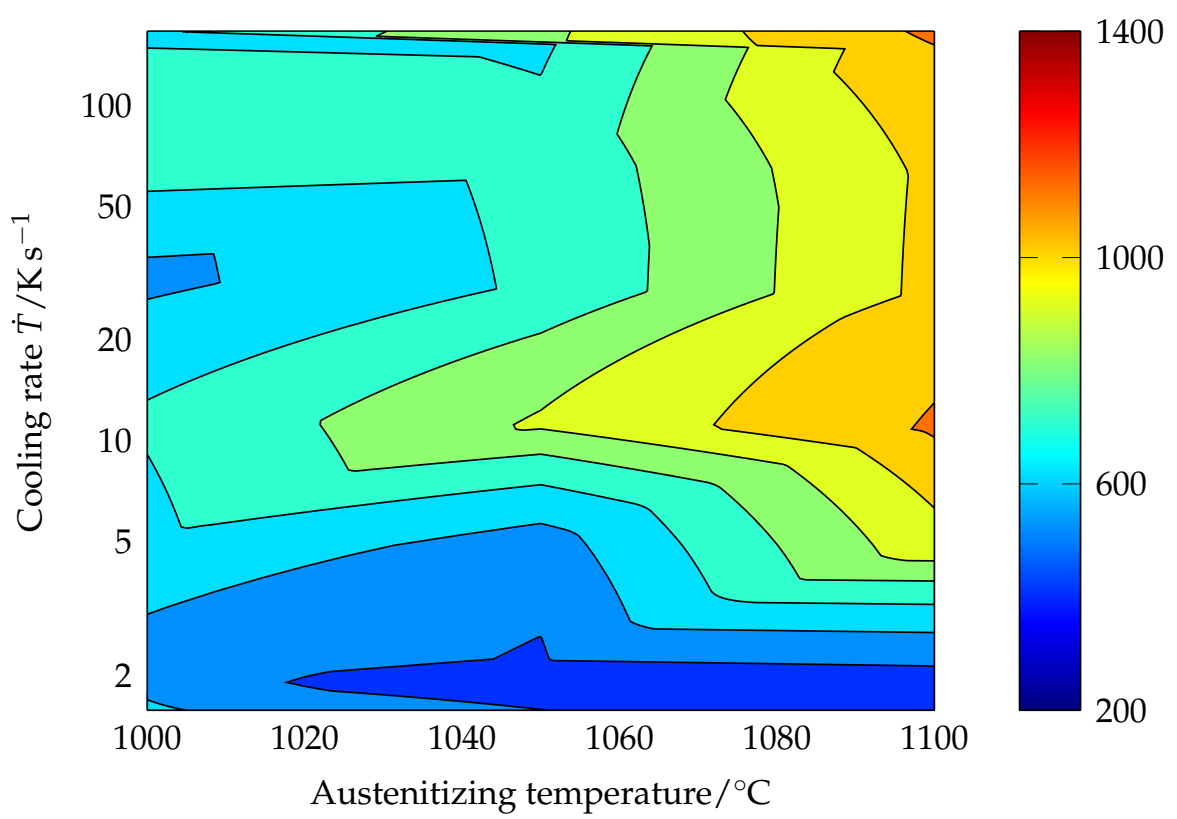

Figure 25. Pitting corrosion potential $\mathrm{Ag} / \mathrm{AgCl}(3 \mathrm{~mol} \mathrm{KCl})$ as a function of the cooling rate $\dot{T}$ (logarithmic scale) and the austenitizing temperature.

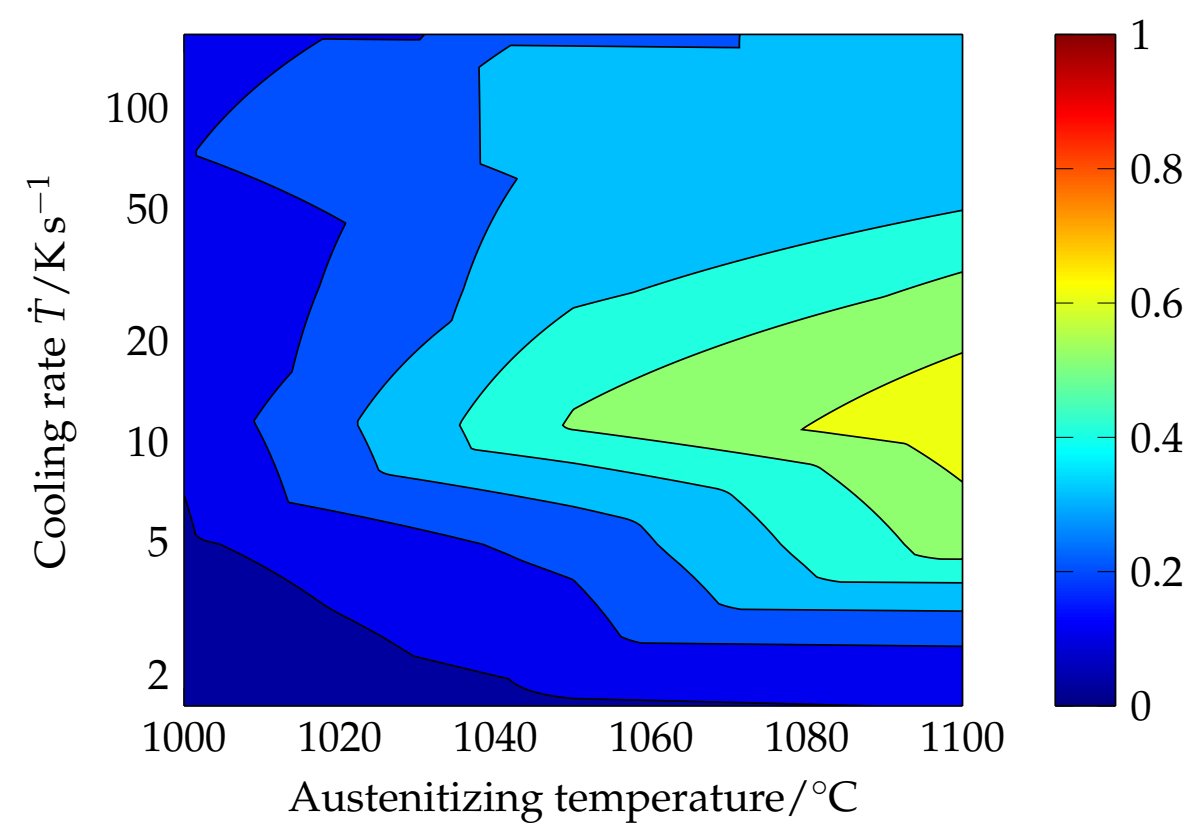

Figure 26. Product of normalized hardness and pitting corrosion potential (equally weighted) as a function of the cooling rate (logarithmic scale) and the austenitizing temperature to determine an optimum process window with high corrosion resistance and hardness. 


\section{Summary}

In this work, the influences of the austenitizing temperature (heat treatment temperature) and the cooling rate on the resulting hardness and corrosion behavior of the steel $\mathrm{X} 30 \mathrm{Cr} 13$ were investigated. By means of FE simulations, the cooling rates could be determined accurately to the respective distances to the quenched end face of Jominy end quench test samples. The influence of the austenitizing temperature on the hardness and corrosion resistance is directly related to the limited temperature stability of the carbides in the austenitic matrix. From a temperature above $1070{ }^{\circ} \mathrm{C}$, the carbides $\left(\mathrm{M}_{23} \mathrm{C}_{6}\right.$, i.e., $\left.\mathrm{Cr}_{23} \mathrm{C}_{6}\right)$ are completely dissolved. Thus, the increasing chromium content leads to better corrosion resistance. With increasing carbon content the hardness increases. As carbon is an austenite stabilizer, a too high carbon content can lead to retained austenite after rapid cooling to room temperature. This leads to a decrease in hardness despite a higher carbon content. In the case of $\mathrm{X} 30 \mathrm{Cr} 13$, the hardness drops slightly when the alloy was austenitized at a temperature of $1100^{\circ} \mathrm{C}$. This indicates that retained austenite is present after austenitizing the alloy at $1100^{\circ} \mathrm{C}$. This was confirmed by the XRD measurements. The mass fraction of retained austenite at $1100^{\circ} \mathrm{C}$ is on average approximately $17-20 \%$. As the stabilizing effect of the carbides is missing at high temperatures, grain growth can be observed, see Figure 15 and Table 6. During cooling, the development of carbide precipitations $\left(\mathrm{M}_{23} \mathrm{C}_{6}\right)$ occurs preferentially at the grain boundaries. This leads to local carbon and chromium depletion, so that the hardness and in particular the corrosion properties are affected. The precipitation kinetics also depend on the austenitizing temperature. This can be seen in the different profiles of hardness and pitting corrosion potentials as a function of the distances from the quenched end face or the cooling rates. By creating diagrams of hardness and corrosion behavior as a function of the austenitizing temperature and cooling rate, suitable process windows for the heat treatment of $\mathrm{X} 30 \mathrm{Cr} 13$ can be derived. In summary, the following statements can be confirmed:

1. With increasing austenitizing temperature, the number and size of the carbides decreases and the contents of the alloying elements in solid solution increase.

2. The content of the alloying elements dissolved in the austenite influences the hardness and the corrosion properties. The higher the carbon content in solid solution in the austenitic as well as in the martensitic phase after cooling is, the higher is the resulting hardness of the martensite. Retained austenite, which lowers hardness, was found at an austenitizing temperature of $1100^{\circ} \mathrm{C}$ with a mass fraction of approximately $17-20 \%$ in the $\mathrm{X} 30 \mathrm{Cr} 13$ studied. The higher the chromium content is, the higher is the pitting corrosion potential. This results in better corrosion resistance.

3. The cooling rate influences the hardness and the corrosion behavior. This is due to the carbide precipitations, especially at the grain boundaries. The influence of the cooling rate is more noticeable at the lower austenitizing temperature of $1000^{\circ} \mathrm{C}$.

4. Carbides, e.g., being formed at the grain boundaries, due to low cooling rates, have a negative effect on the corrosion properties due to local chromium depletion.

5. The hardness is also influenced by the cooling rate due to carbide formation by the proclivity of carbide formation in correlation with the cooling rate, but to a lesser extent than the influence of austenitizing temperature.

6. Grain growth is observed at high austenitizing temperatures, especially when the carbides are almost or completely dissolved in the austenite.

The Jominy end quench test at different austenitizing temperatures allows to show the dependencies of the process variables (austenizitation temperature and cooling rate) and to determine process windows to achieve an optimal combination of hardness and corrosion resistance. The cooling rates vary from approximately $150 \mathrm{~K} \mathrm{~s}^{-1}$ at $1 \mathrm{~mm}$ distance to the quenched end face to approx. $1.6 \mathrm{~K} \mathrm{~s}^{-1}$ at $80 \mathrm{~mm}$ distance to the quenched end face of the Jominy end quench test sample. The recommended cooling rates $\dot{T}$ and austenitizing temperatures $\vartheta_{A}$ are shown in Table 10. Note that no subsequent heat treatment, such as tempering, took place. 
Table 10. Recommended cooling rates $\dot{T}$ and austenitizing temperatures $\vartheta_{A}$ to obtain high hardness and corrosion resistance.

\begin{tabular}{ccc}
\hline Property & \multicolumn{1}{c}{} & $\vartheta_{A}$ \\
\hline Hardness $/ \mathrm{HV} 10$ & $5 \mathrm{~K} \mathrm{~s}^{-1}$ to $40 \mathrm{~K} \mathrm{~s}^{-1}$ & $1050^{\circ} \mathrm{C}$ \\
Pitting corrosion potentials & $5 \mathrm{~K} \mathrm{~s}^{-1}$ to $40 \mathrm{~K} \mathrm{~s}^{-1}$ & $1100^{\circ} \mathrm{C}$ \\
$\mathrm{Ag} / \mathrm{AgCl}(3 \mathrm{~mol} \mathrm{KCl}) / \mathrm{mV}$ & & \\
\hline
\end{tabular}

A combination of high hardness with good pitting corrosion resistance can be achieved at high austenitizing temperatures $\left(\vartheta_{A} \geq 1050{ }^{\circ} \mathrm{C}\right)$ and fast cooling rates $\left(\dot{T} \geq 5 \mathrm{~K} \mathrm{~s}^{-1}\right)$. At a austenitizing temperature of $1100^{\circ} \mathrm{C}$, a mass fraction of more than $10 \%$ retained austenite is present. If the cooling rates are too high $\left(\dot{T} \geq 40 \mathrm{~K} \mathrm{~s}^{-1}\right)$, brittle behavior and hardening cracks can occur, which can lead to a drop in hardness and a wider spread of the corrosion resistance. Therefore, subsequent tempering is necessary. Note that hardening cracks can also occur even at slow cooling rates $\dot{T}$ if cooling below martensite start $\mathrm{M}_{\mathrm{S}}$ is too fast. The cooling rate $\dot{T}$ is thus not only decisive between $800^{\circ} \mathrm{C}$ and $500^{\circ} \mathrm{C}$, but also plays a role between martensite start $\mathrm{M}_{\mathrm{S}}$ and martensite finish $\mathrm{M}_{\mathrm{F}}$ for the high-alloy martensitic stainless steels.

\section{Conclusions}

The results of this research are based on a methodology that combine thermodynamic calculations, numerical simulations as well as experimental determinations and validations. They provided a reliable establishment of optimized process windows for the $\mathrm{X} 30 \mathrm{Cr} 13$ alloy that can be extended in the future to include additional properties such as tensile strength or toughness.

Another major advantage of the methodology shown is the minimization of experimental effort, since cooling rates $\dot{T}$ between $800^{\circ} \mathrm{C}$ and $500^{\circ} \mathrm{C}$ of approximately $400 \mathrm{~K} \mathrm{~s}^{-1}$ at the quenched end face to approximately $1.5 \mathrm{~K} \mathrm{~s}^{-1}$ at the end of the sample are varied with one Jominy end quench test. By additionally varying the austenitizing temperature, it is thus possible to cover a large practical test area with a low experimental effort.

The presented methodology allows the calculation of the cooling rates and the procedure for their validation. This makes it possible to reliably assign cooling rates to the experimentally determined results, which are available as a function of the distance to the face of the Jominy end quench test.

By combining the hardness and corrosion properties, a methodology is also shown which makes it possible to determine optimum process windows for the heat treatment of $\mathrm{X} 30 \mathrm{Cr} 13$. By balancing the required functional properties, process windows can be determined that are specifically tailored to the application in a given case. This provides a contribution to application-controlled process and resource optimization.

In future work, the process window(s) with regard to the lowest energy consumption and at the same time the required hardness and corrosion resistance properties will be optimized. Furthermore, the influence of subsequent heat treatments, such as tempering, on hardness and corrosion behavior will be investigated.

Author Contributions: Conceptualization, P.L., P.B., E.M.-G., and T.G.; methodology, P.L.; experimental trials, P.L.; software, P.L.; validation, P.L.; formal analysis, P.L.; resources, V.K. and T.L.; writing-original draft preparation, P.L.; writing-review and editing, E.M.-G., P.B., and T.G.; visualization, P.L.; supervision, T.G., V.K., and T.L.; funding acquisition, E.M.-G., P.L., V.K., and T.L. All authors have read and agreed to the published version of the manuscript.

Funding: Funded by the Deutsche Forschungsgemeinschaft (DFG, German Research Foundation)Projekt number 334485458. The publication of this article was funded by Chemnitz University of Technology.

Institutional Review Board Statement: Not applicable.

Informed Consent Statement: Not applicable. 


\title{
Data Availability Statement: Not applicable.
}

Acknowledgments: The authors gratefully acknowledge the support of the DFG.

Conflicts of Interest: The authors declare no conflict of interest.

\author{
Abbreviations \\ The following abbreviations are used in this manuscript: \\ EDX energy-dispersive X-ray spectroscopy \\ FEM finite element method \\ SEM scanning electron microscopy
}

\section{References}

1. Thermomechanische Behandlung von Hochlegierten Martensitischen Nichtrostenden Stählen für Komplexe Bauteile, DFG (German Research Foundation)—Projekt Number 334485458. Available online: https://gepris.dfg.de/gepris/projekt/334485458 (accessed on 2 July 2021).

2. Rosemann, P. Einfluss der Wärmebehandlung auf die Korrosionsbeständigkeit Martensitisch Nichtrostender Stähle. Ph.D. Thesis, Otto-von-Guericke-Universität Magdeburg, Magdeburg, Germany, 2017.

3. Gümpel, P. Rostfreie Stähle, 4th ed.; Renningen Expert-Verl.: Renningen, Germany, 2008; ISBN 978-3-8169-2689-4.

4. Rosemann, P.; Müller, C.; Kauss, N.; Halle, T. Einfluss der Wärmebehandlung auf Mikrostruktur und Korrosionsverhalten kohlenstoffhaltiger nichtrostender Stähle. In Tagungsband zum 17, Proceedings of the Werkstofftechnischen Kolloquium in Chemnitz, Chemnitz, Germany, 11-12 September 2014; Wielage, B., Ed.; Eigenverl.: Chemnitz, Germany, 2014; pp. 103-112. ISBN 978-3-00046877-3.

5. García de Andrés, C.; Alvarez, L.F.; Lopez, V. Effects of carbide-forming elements on the response to thermal treatment of the X45Cr13 martensitic stainless steel. J. Mater. Sci. 1998, 33, 4095-4100. [CrossRef]

6. Macherauch, E. V16 Martensitische Umwandlung. In Praktikum in Werkstoffkunde; Friedr. Vieweg \& Sohn Verlagsgesellschaft mbh: Braunschweig, Germany, 1990; pp. 80-84.

7. Mehner, T.; Landgraf, P.; Haack, E.; Scharf, I.; Grund, T.; Lampke, T. Pitting corrosion behavior of a laser hardened, high-alloyed steel. IOP Conf. Ser. Mater. Sci. Eng. 2019. ISSN 1757899X. [CrossRef]

8. García de Andrés, C.; Caruana, G.; Alvarez, L. Control of M23C6 carbides in $0.45 \mathrm{C}-13 \mathrm{Cr}$ martensitic stainless steel by means of three representative heat treatment parameters. Mater. Sci. Eng. A 1998, A241, 211-215.

9. Rosemann, P.; Kauss, N.; Müller, C.; Halle T. Influence of solution annealing temperature and cooling medium on microstructure, hardness and corrosion resistance of martensitic stainless steel X46Cr13. Mater. Corros. 2015, 66, 1068-1076. [CrossRef]

10. Zhu, Q.; Li, J.; Shi, C.; Yu, W. Effect of quenching process on the microstructure and hardness of high-carbon martensitic stainless steel. J. Mater. Eng. Perform. 2015, 24, 4313-4321. [CrossRef]

11. Yang, Y.; Zhao, H.; Dong, H. Carbide evolution in high-carbon martensitic stainless cutlery steels during austenitizing. J. Mater Eng. Perform. 2020, 26, 3868-3875. [CrossRef]

12. Bonagani, S.; Kain, V.; Kumar, N.; Donthula, H. Effect of austenitization-cooling on microstructure and localized corrosion behavior of 13Cr martensitic stainless steel. J. Mater. Eng. Perform. 2021, 30, 2291-2299. [CrossRef]

13. Meza-García, E.; Birnbaum, P.; Landgraf, P.; Grund, T.; Lampke, T.; Kräusel, V. Thermomechanical Treatment of Martensitic Stainless Steels Sheets and Its Effects on Their Deep Drawability and Resulting Hardness in Press Hardening. Metals 2020, 10, 1536. [CrossRef]

14. Birnbaum, P.; Meza-García, E.; Landgraf, P.; Grund, T.; Lampke, T.; Kräusel, V. Experimental and Numerical Assessment of the Hot Sheet Formability of Martensitic Stainless Steels. J. Manuf. Mater. Process. 2020, 4, 122. [CrossRef]

15. Börner, R.; Landgraf, P.; Kimme, S.; Titsch, C.; Lampke, T.; Schubert, A. Fundamental Investigations in Tool Wear and Characteristics of Surface Microstructure for Ultrasonic Vibration Superimposed Machining of Heat-Treated X46Cr13 Steel Using Different Cutting Materials. J. Manuf. Mater. Process. 2021, 5, 27. [CrossRef]

16. DIN EN ISO 642:2000-01. Stirnabschreckversuch (Jominy-Versuch): Steel_Hardenability Test by End Quenching (Jominy Test) (ISO 642:1999); German Version EN ISO 642:1999; Beuth Verl.: Berlin, Germany, 2000.

17. Weidmann, E.; Guesnier, A.; Taylor, B. Struers Application Notes-Metallographic Preparation of Stainless Steel; Struers A/S: Copenhagen, Denmark; Struers Ltd.: Glasgow, UK, 2019.

18. DIN EN ISO 643:2013-05. Steels-Micrographic Determination of the Apparent Grain Size (ISO 643:2012); German Version EN ISO 643:2012; Beuth Verl.: Berlin, Germany, 2013.

19. JMatPro PRACTICAL SOFTWARE FOR MATERIALS PROPERTIES. Available online: https://www.sentesoftware.co.uk/jmatpro (accessed on 16 June 2021).

20. Ilschner, B.; Singer, R.F. Ausscheidung von Ferrit aus Austenit in Stählen. Eutektoider Zerfall. In Werkstoffwissenschaften und Fertigungstechnik; Springer Vieweg: Berlin, Germany, 2016. [CrossRef]

21. Berns, H. Die Bedeutung der $\mathrm{t}_{10 / 7}$-Zeit für die Wärmebehandlung hochlegierter Stähle. HTM J. Heat Treat. Mater. 2010, 65, 182-188. [CrossRef] 
22. Lu, Y.; Yu, H.; Cai, X.; Rong, Y.; Sisson, R.D. Martensite lattice parameter measured by modern X-ray diffraction in Fe-C alloy. In Proceedings of the 23rd International Federation of Heat Treatment and Surface Engineering Congress (IFHTSE 2016), Savannah, GA, USA, 18-21 April 2016; pp. 404-409.

23. Lu, Y.; Yu, H.; Sisson, R.D. The effect of carbon content on the c/a ratio of as-quenched martensite in Fe-C alloys. Mater. Sci. Eng. A 2017, 700, 592-597. [CrossRef] 